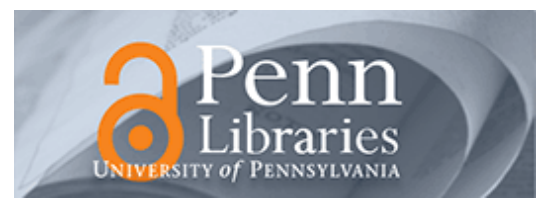

University of Pennsylvania

ScholarlyCommons

Management Papers

Wharton Faculty Research

$11-2011$

\title{
Balance Within and Across Domains: The Performance Implications of Exploration and Exploitation in Alliances
}

Dovev Lavie

Jingoo Kang

Lori Rosenkopf

University of Pennsylvania

Follow this and additional works at: https://repository.upenn.edu/mgmt_papers

Part of the Business Administration, Management, and Operations Commons

\section{Recommended Citation}

Lavie, D., Kang, J., \& Rosenkopf, L. (2011). Balance Within and Across Domains: The Performance Implications of Exploration and Exploitation in Alliances. Organization Science, 22 (6), 1517-1538. http://dx.doi.org/10.1287/orsc.1100.0596

This paper is posted at ScholarlyCommons. https://repository.upenn.edu/mgmt_papers/123

For more information, please contact repository@pobox.upenn.edu. 


\title{
Balance Within and Across Domains: The Performance Implications of Exploration and Exploitation in Alliances
}

\begin{abstract}
Organizational research advocates that firms balance exploration and exploitation, yet it acknowledges inherent challenges in reconciling these opposing activities. To overcome these challenges, such research suggests that firms establish organizational separation between exploring and exploiting units or engage in temporal separation whereby they oscillate between exploration and exploitation over time. Nevertheless, these approaches entail resource allocation trade-offs and conflicting organizational routines, which may undermine organizational performance as firms seek to balance exploration and exploitation within a discrete field of organizational activity (i.e., domain). We posit that firms can overcome such impediments and enhance their performance if they explore in one domain while exploiting in another. Studying the alliance portfolios of software firms, we demonstrate that firms do not typically benefit from balancing exploration and exploitation within the function domain (technology versus marketing and production alliances) and structure domain (new versus prior partners). Nevertheless, firms that balance exploration and exploitation across these domains by engaging in research and development alliances while collaborating with their prior partners, or alternatively, by forming marketing and production alliances while seeking new partners, gain in profits and market value. Moreover, we reveal that increases in firm size that exacerbate resource allocation trade-offs and routine rigidity reinforce the benefits of balance across domains and the costs of balance within domains. Our domain separation approach offers new insights into how firms can benefit from balancing exploration and exploitation. What matters is not simply whether firms balance exploration and exploitation in their alliance formation decisions but the means by which they achieve such balance.
\end{abstract}

\section{Keywords}

strategy and firm performance, strategy and policy, strategic alliance networks, ambidextrous organizations, interorganizational relationships, organization and management theory, organizational learning, exploration and exploitation

\section{Disciplines}

Business Administration, Management, and Operations 


\section{Balance Within and Across Domains: The Performance Implications of Exploration and Exploitation in Alliances ${ }^{\dagger}$ \\ DOVEV LAVIE}

Faculty of Industrial Engineering and Management

Technion - Israel Institute of Technology

Haifa 32000, Israel

Tel: 972-4-8294435

Fax: 972-4-8295688

Email: dlavie@ie.technion.ac.il

\section{JINGOO KANG}

Management Department

The Wharton School

University of Pennsylvania

3620 Locust Walk, Philadelphia, PA 19104, USA

Tel: (215) 898-4191

Fax: (215) 898-0401

Email: jingoo@wharton.upenn.edu

\section{LORI ROSENKOPF}

Management Department

The Wharton School

University of Pennsylvania

3620 Locust Walk, Philadelphia, PA 19104, USA

Tel: (215) 898-6723

Fax: (215) 898-0401

Email: rosenkopf@wharton.upenn.edu

First version: May 4, 2008

Revised: September 29, 2008

Current version: January 27, 2010

Submitted to the $7^{\text {th }}$ Atlanta Competitive Advantage Conference

\footnotetext{
${ }^{\dagger}$ We appreciate the feedback received from Dan Levinthal and Frank Rothaermel as well as from seminar participants at the Wharton School, the University of Maryland, Scuola Interpolitecnica di Dottoratom, Politecnico di Bari, the IESE Business School, and the Technion. This paper has been presented at the 2008 International Strategic Management Society Conference in Cologne, Germany, and the $3^{\text {rd }}$ Israel Strategy Conference held in Be'er Sheva, Israel, 2009. An abbreviated version of this paper has been published in the Academy of Management Best Paper Proceedings of the 2009 annual conference in Chicago, Illinois. The data used in this paper rely in part on Dovev Lavie's doctoral dissertation, "The Interconnected Firm: Evolution, Strategy, and Performance." Dovev Lavie acknowledges the financial support of the Sloan Industry Studies program of the Alfred. P. Sloan Foundation, the Landau Fellowship, which is supported by the Taub Foundation, and the Elson/Shapiro Families Research Fund. Jingoo Kang and Lori Rosenkopf acknowledge the financial support of the Mack Center for Technological Innovation at the Wharton School of the University of Pennsylvania.
} 


\title{
Balance Within and Across Domains: The Performance Implications of Exploration and Exploitation in Alliances
}

\begin{abstract}
Organizational research advocates that firms balance exploration and exploitation yet acknowledges inherent challenges in reconciling these opposing activities. To overcome these challenges, such research suggests that firms establish organizational separation between exploring and exploiting units or engage in temporal separation whereby they oscillate between exploration and exploitation over time. Nevertheless, these approaches entail resource allocation tradeoffs and conflicting organizational routines, which may undermine organizational performance as firms seek to balance exploration and exploitation within a discrete field of organizational activity (i.e., domain). We posit that firms can overcome such impediments and enhance their performance if they explore in one domain while exploiting in another. Studying the alliance portfolios of software firms, we demonstrate that firms do not typically benefit from balancing exploration and exploitation within the function domain (technology versus marketing and production alliances) and structure domain (new versus prior partners). Nevertheless, firms that balance exploration and exploitation across these domains by engaging in R\&D alliances while collaborating with their prior partners, or alternatively by forming marketing and production alliances while seeking new partners, gain in profits and market value. Moreover, we reveal that increases in firm size that exacerbate resource allocation tradeoffs and routine rigidity reinforce the benefits of balance across domains and the costs of balance within domains. Our domain separation approach offers new insights into how firms can benefit from balancing exploration and exploitation. What matters is not simply whether firms balance exploration and exploitation in their alliance formation decisions but the means by which they achieve such balance.
\end{abstract}




\section{Introduction}

The notion of exploration and exploitation has received much attention in management research since it was introduced by March (1991: 71): "Exploration includes things captured by terms such as search, variation, risk taking, experimentation, play, flexibility, discovery, innovation. Exploitation includes such things as refinement, choice, production, efficiency, selection, implementation, execution." According to Levinthal and March (1993), exploration enables the creation of new knowledge, whereas exploitation supports the refinement and use of existing knowledge. Prior research has advocated that "maintaining an appropriate balance between exploration and exploitation is a primary factor in system survival and prosperity" (March 1991: 71), underscoring the positive performance implications of such balance. Surprisingly, despite extensive discussion of the merits of balance, with few exceptions (He and Wong 2004; Sidhu, Commandeur, and Volberda 2007), empirical evidence of performance effects has been mostly furnished by anecdotal case studies (e.g., Tushman and O'Reilly 1996), offering limited support to this balance hypothesis. In this study we suggest that prior research has underestimated the organizational impediments associated with firms' efforts to balance exploration and exploitation, and that the performance implications of such balance depend on the means by which firms pursue this balance.

Established approaches for balancing exploration and exploitation, namely temporal separation and organizational separation, impose managerial challenges and organizational impediments that may offset the payoffs from balancing these two activities. Rooted in the notion of bounded rationality and sequential attention to divergent goals (Cyert and March 1963), temporal separation entails oscillating between exploration and exploitation over time (Gibson and Birkinshaw 2004), so that firms explore at one point in time and then exploit at another (Brown and Eisenhardt 1997). Nevertheless, such transitions are not trivial, and their implementation requires adaptability and agility. In turn, literature on the ambidextrous organization has advocated simultaneous pursuit of exploration and exploitation via organizational separation, whereby firms build dual governance into their organization (Duncan 1976) with organizational units exclusively dedicated to either activity (Benner and Tushman 2003; O'Reilly and Tushman 2004; Tushman and O'Reilly 1996). Hence, this approach seemingly overcomes the tradeoff 
between these conflicting activities: "the learning, resources, and routines necessary for exploration and exploitation are different. As such, they may be delegated within a group or organization so that both can be achieved simultaneously" (Gupta, Smith, and Shalley 2006: 696). Nevertheless, maintaining separate organizational units creates operational redundancy and merely relegates the challenge of coordinating exploration and exploitation to the top management team. In the current study we contend that these organizational impediments can outweigh the benefits of balance, so that firms that simultaneously explore and exploit may suffer negative performance consequences. Furthermore, we advance the domain separation approach that relieves firms from some inherent tradeoffs associated with these established approaches, and thus can enhance firms' abilities to successfully balance exploration and exploitation.

We maintain that the limited empirical support for March's balance hypothesis can be ascribed to the attempts of prior research to study the implications of balance between exploration and exploitation only within a single domain, i.e., within a discrete field of organizational activity, such as in the function domain wherein a firm can either engage in innovation or commercialization of technologies. This mode of balance is analogous to a seesaw that seeks a delicate equilibrium between conflicting loads imposed on its opposite sides. Thus, firms that follow temporal or organizational separation face resource allocation tradeoffs and need to maintain conflicting routines within a particular domain. In contrast, we consider how firms can balance their exploration and exploitation tendencies not only within but also across discrete domains which together describe the organizational activity in question (e.g., Lavie and Rosenkopf 2006; Rosenkopf and Nerkar 2001). Acknowledging the prevalence of multiple domains in which firms can engage in exploratory and exploitative activities, such domain separation does not entail separate organizational units with distinctive sets of conflicting routines. Instead, it offers flexibility for firms to pursue exploration in one domain and exploitation in the other as long as balance is maintained across domains. We expect such balance to enhance firm performance by maintaining both novelty and efficiency while dislodging the firm from the inherent tradeoffs between exploration and exploitation. The benefits of balance across domains are expected to intensify with firm size because operating on a large scale entails more rigid routines, which makes it more difficult to reconcile discrepancies within domains. 
Our study examines these predictions in the context of alliance portfolios. Firms rely on alliances both to explore new opportunities and to leverage existing skills (Koza and Lewin 1998 2000; Rothaermel 2001). In particular, scholars have noted with respect to the value chain function of alliances that exploration enables the acquisition of new capabilities (Mowery, Oxley, and Silverman 1996), whereas exploitation supports product commercialization (Rothaermel 2001). Prior research indicates that firms tend to balance exploration and exploitation in their alliance portfolios (Lavie and Rosenkopf 2006). However, the only evidence on the performance effects of balance reveals reduced resource accumulation as a result of structural balance in a firm's tendency to explore new alliance relationships versus exploit prior ties to partners (Lin, Yang, and Demirkan 2007). The implications of balance within and across these domains have thus remained ambiguous. Prior research does not fully account for balancing effects, since it typically limits its investigation to a single domain.

We conceptualize the domain separation approach based on the well-established distinction between the function domain (knowledge-generating versus knowledge-leveraging alliances) and the structure domain (new versus prior partners). Even though one may specify an alliance relationship along various dimensions such as industry focus or partners' cultural fit, prior research on exploration and exploitation in alliances has almost exclusively focused on the function and structure domains, identifying them as most relevant for alliance formation decisions (e.g., Beckman, Haunschild, and Phillips 2004; Grant and Baden-Fuller 2004; Koza and Lewin 1998; Lavie and Rosenkopf 2006; Lin et al. 2007; Park et al. 2002; Rothaermel 2001; Rothaermel and Deeds 2004). We argue that in the context of a firm's alliances, resource allocation tradeoffs and conflicting organizational routines result in negative performance implications when firms balance exploration and exploitation within the function and structure domains. In turn, domain separation can serve as an effective approach for achieving balance between exploration and exploitation. Our approach reconciles opposing perspectives on the merits of balancing exploration and exploitation by revealing that some forms of balance are more effective than others.

Studying the alliances of U.S.-based software firms during 1990-2001, we furnish evidence on the performance effects of balance within and across the function and structure domains. In accordance with 
the domain separation approach, we find negative effects of balance within the structure domain (tendency to seek proportional representation of new versus prior partners in an alliance portfolio) on firms' market value and net profit. In turn, balancing exploration and exploitation across the function and structure domains (e.g., forming $R \& D$ alliances yet engaging in recurrent alliances with prior partners) improves these performance outcomes. Furthermore, we demonstrate that as firms grow, balancing within domains becomes less effective while balancing across domains becomes a more effective means for enhancing performance. These findings shed new light on March's balance hypothesis and contribute to emerging research on ambidexterity and alliance portfolios.

\section{Theoretical Background}

Interfirm alliances enable firms to share and exchange resources for the purpose of jointly developing or providing technologies, products, or services (Gulati 1998). In line with Levinthal and March (1993), Koza and Lewin (1998) suggested that firms may establish alliances to jointly exploit their existing knowledge or to explore new opportunities. Most prior research has followed this distinction between exploration and exploitation in alliances based on the value chain function that alliances serve (e.g., Park, Chen, and Gallagher 2002; Rothaermel 2001; Rothaermel and Deeds 2004). According to this tradition, a firm that collaborates with its partners in upstream activities of the value chain, such as R\&D initiatives that may result in innovative technologies or products, engages in exploration in the function domain. In contrast, a firm that uses alliances for performing downstream activities of the value chain, such as commercialization or application of existing technologies, pursues exploitation in that domain. Hence, scholars have associated a firm's tendency to acquire and generate new knowledge through exploration with R\&D alliances, contrasting them with marketing and production alliances that serve for exploitation by leveraging, integrating, and implementing existing knowledge (Grant and Baden-Fuller 2004; Lavie and Rosenkopf 2006; Park et al. 2002; Rothaermel 2001; Rothaermel and Deeds 2004).

Besides the function domain, recent research on alliances has acknowledged efforts to explore and 
exploit in the structure domain (e.g., Lavie and Rosenkopf 2006; Lin et al. 2007). ${ }^{1}$ Exploration in the structure domain refers to a firm's tendency to seek opportunities by forming alliances with new partners that lack prior ties to the firm, wherein the firm expands its network boundaries beyond the immediate structure of its alliance portfolio. Thus, in accordance with March's (1991) notion of exploration, exploration in the structure domain creates new opportunities but increases risk and uncertainty because the firm cannot rely on prior experience with its new partners. In turn, exploitation in the structure domain refers to a firm's efforts to consolidate its alliance portfolio by forming recurrent alliances with a select group of partners with whom the firm has established ties for accessing resources that reside within its alliance portfolio (Beckman et al. 2004; Lin et al. 2007). Per March's (1991) notion of exploitation, alliances with prior partners reinforce the firm's current knowledge base (Beckman et al. 2004), leverage its partnering experience (Hoang and Rothaermel 2005) and rely on accumulated trust to enhance the predictability and reliability of collaboration (Baum, Rowley, Shipilov, and Chuang 2005; Chung, Singh, and Lee 2000; Gulati 1995b; Gulati and Gargiulo 1999; Li and Rowley 2002). Hence, firms' tendencies to explore or exploit manifest in both the function and structure domains of alliances.

Prior research has identified some antecedents to firms' tendencies to engage in exploration and exploitation within either the function or the structure domains of alliance formation. Such tendencies may lead to imbalance between exploration and exploitation within each domain. Some studies identify industry conditions such as market uncertainty as drivers of either exploration or exploitation (Beckman et al. 2004; Rothaermel 2001). Other studies consider firm-specific antecedents of exploration and exploitation tendencies (Park et al., 2002; Rothaermel and Deeds 2004), yet little is known about what guides firms' decisions to explore versus exploit in their alliance formation decisions. In attempt to reconcile inconsistent findings and explain firms' attempts to balance exploration and exploitation in

\footnotetext{
${ }^{1}$ In addition to the function and structure domains, Lavie and Rosenkopf (2006) refer to exploration and exploitation in the attribute domain, considering how the characteristics of partners differ from those of the firm's prior partners. Together, these three domains effectively describe an alliance by considering the value chain function of the alliance, the structural position of the partners, and their relative attributes. However, the characteristics by which partners differ are themselves multidimensional and may reveal inconsistent patterns. We thus exclude the attribute domain and focus on the function and structure domains in accordance with established research on exploration and exploitation in alliances.
} 
alliances, Lavie and Rosenkopf (2006) demonstrated that partnering experience leads to exploration in the function domain (shifting from marketing and production alliances to R\&D alliances) and exploitation in the structure domain (shifting from new to prior partners). They further reveal patterns of slack-induced search whereby profitable firms engage in more extensive function exploration, and document path dependence in exploration versus exploitation tendencies within each domain. Finally, they show how firms balance these tendencies across domains by shifting from existing to new partners while engaging in more marketing and production alliances as opposed to R\&D alliances. Nevertheless, these studies do not uncover the performance implications of such balance.

In this regard, prior research suggests that exploration and exploitation are both essential for organizational performance. Whereas exploitation leverages existing knowledge and relationships, exploration generates new knowledge and social capital. Firms that engage in exploration but neglect exploitation may end up with undeveloped ideas and unrealized opportunities. In turn, overinvestment in exploitation at the expense of exploration may exhaust firms' opportunities and render their competencies obsolete (March 1991). Hence, firms that simultaneously explore and exploit are expected to achieve superior performance relative to firms that emphasize one activity at the expense of the other (Tushman and O'Reilly 1996). This balance hypothesis has served scholars in conjecturing about the merits of balancing exploration and exploitation in alliance portfolios (e.g., Lin et al. 2007).

According to prior research, alliances extend a firm's boundaries so it can engage in value chain activities that are otherwise unavailable given its internal resources and market opportunities (Dyer 2000; Gulati 1999; Lavie 2006). A firm that restricts its portfolio to R\&D alliances forgoes opportunities that cannot be efficiently tapped by its internal organization as a result of limited market access. In turn, a firm that limits its portfolio to marketing and production alliances may fail to internalize external knowledge that cannot be developed internally (Hagedoorn 1993; Mowery et al. 1996; Rothaermel 2001). Thus, prior research suggests that an alliance portfolio that overemphasizes either exploration or exploitation within the function domain is sub-optimal (Hoffmann 2007). Similarly, alliances with new partners introduce new opportunities, diverse information, and novel ideas beyond the reach of a firm's immediate alliance 
portfolio (Stuart 2000). In turn, recurrent alliances with prior partners leverage interfirm trust and established routines for tight coordination, joint problem solving, and conflict resolution (Gulati 1995a; Rowley, Behrens, and Krackhardt 2000; Kale, Singh, and Perlmutter 2000; Uzzi 1996). Hence, prior research suggests that a firm that fails to balance exploration and exploitation within the structure domain may not be able to fully capitalize on the benefits of its alliance portfolio, and its performance may suffer as a result (Lin et al. 2007). Despite the compelling rationale of the balance hypothesis, empirical evidence in support of this premise has been limited at best. We next argue that resource allocation tradeoffs and conflicting organizational routines may offset the benefits of balance within domains. We then propose that balance across domains generates more favorable performance implications in alliances.

\section{Hypotheses}

Despite the potential merits of balance in the function and structure domains, exploration and exploitation are often at odds, requiring firms to manage tradeoffs when pursuing these activities simultaneously. These tradeoffs are instigated by competition for scarce resources that support both activities and by the fact that these activities rely on distinctive modes of organizational behavior and routines (March 1991). The self-reinforcing nature of these routines strengthens the dominant activity while driving out the other (Levinthal and March 1993; March 1991). Consequently, most firms would find it challenging to reconcile the tension between exploration and exploitation (Tushman and O'Reilly 1996). Firms that strive to balance exploration and exploitation encounter cultural, structural, demographic, and process incongruities and also face conflicts between their exploring and exploiting units (Abernathy 1978; Benner and Tushman 2003; Tushman, Anderson, and O’Reilly 1997). The increased demand for operational resources and the coordination challenges imposed by conflicting routines can thus impair performance. A firm's use of alliances enables it to attenuate internal resource allocation constraints by sharing resource investments with partners. However, similar tension between exploration and exploitation emerges when the firm attempts to balance these activities in its alliance portfolio. Resource allocation constraints and organizational conflicts merely shift from internal units to the alliance organization, yet remain detrimental. 
In particular, a firm may face resource allocation tradeoffs when balancing exploration and exploitation within the function domain. Whereas $R \& D$ alliances entail risky investments in new technologies, marketing and production alliances commercialize existing knowledge in search of immediate payoffs. Thus, the firm faces a dilemma in supporting these distinctive types of alliances in its portfolio given the disparity in their objectives and associated risk levels. Supporting collaborative R\&D initiatives may come at the expense of leveraging established technologies with marketing partners and enhancing operational efficiency. The tradeoffs in allocating resources to $R \& D$ alliances versus marketing and production alliances may diminish the effectiveness of the alliance portfolio and its responsiveness to emerging market conditions, and thus undermine its contribution to firm performance.

Moreover, organizational routines that support knowledge-generating alliances contradict those that underlie knowledge-leveraging alliances throughout the alliance lifecycle. Specifically, the former favor collaborating with innovative and flexible partners whereas the latter favor engaging partners that underscore productivity and stability. Additionally, function exploration entails search, evaluation, and internalization of external knowledge (Zahra and George 2002), whereas function exploitation necessitates integration, application, and refinement of existing knowledge (Grant and Baden-Fuller 2004). These conflicting processes lead to inconsistencies as a firm seeks to balance exploration and exploitation in its alliance portfolio. Finally, the criteria for evaluating the outcomes of these two types of alliances differ, which can lead to improper feedback and negative learning effects across alliances. A balance-seeking firm may fail to develop relevant partnering routines because departure from a consistent pattern of repetitive behavior impedes the evolution of organizational routines (Nelson and Winter 1982; Zollo, Reuer, and Singh 2002). Such disparity in the alliance portfolio may also result in misapplication of partnering routines that fit one type of alliance but not the other. Hence, balancing exploration and exploitation in the function domain can impair firm performance.

Similarly, in the structure domain, firms encounter tradeoffs in resource allocation and inconsistent organizational routines when seeking to balance formation of new ties with elaboration of existing ties (Beckman et al. 2004; Lin et al. 2007). Whereas recurrent alliances with prior partners entail local search 
and the nurturing of strong ties with a small set of partners, alliances with new partners encourage boundary spanning and the casting of a broad net using indirect contacts and referrals (Burt 2000; Rosenkopf and Nerkar 2001). Because local search and boundary spanning require distinctive orientations, a firm that balances exploration and exploitation within the structure domain must develop conflicting partner selection routines, which impairs specialization and attenuates the efficiency of alliance formation. The potential substitution between resources offered by established partners and those furnished by prospective partners can lead to conflict and sub-optimal partner selection. Furthermore, whereas alliances with new partners often rely on formal governance mechanisms such as explicit contractual safeguards, alliances with prior partners can leverage informal agreements and interfirm trust (Gulati and Singh 1998; Reuer and Arino 2007). A firm that balances exploration and exploitation needs to juggle these conflicting governance modes and may fail to develop consistent practices for managing its alliances. Misapplication of partnering routines can then lead to opportunistic behavior when blindly trusting new partners or to inefficiency and tension when enforcing formal governance in alliances with long-time partners. Partners may also become dissatisfied with preferential treatment or inconsistent arrangements employed in otherwise equivalent alliances. These caveats compromise the firm's ability to benefit from simultaneous engagement in exploration and exploitation within domains. Consequently, a firm that balances exploration and exploitation within the function and structure domains may undermine the effectiveness of its alliance portfolio and suffer negative performance consequences.

H1. Firm performance will be negatively related to balance between exploration and exploitation within (a) the function and (b) the structure domains of alliance formation decisions.

We have noted that balancing exploration and exploitation within domains incurs inherent organizational tradeoffs and impediments that may offset innovativeness and productivity gains from alliance portfolios. Nevertheless, a firm can avoid these challenges and still enjoy the benefits of balance by exploring in one domain while exploiting in another. For example, a firm may form recurrent $R \& D$ alliances (engaging in function exploration) with existing partners (engaging in structure exploitation) to generate new knowledge while leveraging familiarity and established partnering routines. Alternatively, it 
can extend its market reach for existing products (engaging in function exploitation) by signing up many new resellers (engaging in structure exploration). Such balance across domains generates important benefits and at the same time transcends the impediments associated with balance within domains.

By focusing on R\&D alliances and working with familiar partners, or instead, concentrating on collaborative marketing and production while seeking new partners, the firm can simultaneously generate new opportunities and leverage its accumulated experience while reducing its exposure to excessive risk. Following March's (1991) broad notions of exploration and exploitation, the exploratory and exploitative activities need not take place in a single domain as long as the firm finds ways to embrace both established and emerging stimuli in its alliance portfolio. Hence, the firm can balance exploration and exploitation while supporting specialization within each domain. Specifically, the firm can develop functional expertise in either collaborative R\&D or joint marketing and production activities and thus enhance the effectiveness of its alliances. At the same time it can nurture distinctive relational capabilities (Kale, Dyer, and Singh 2002) for collaborating with a coherent group of established partners or rather specialize in managing an evolving portfolio of new partners. Hence, the firm can seek opportunities by investing either in new knowledge development or in the heterogeneity of partners in its portfolio. In addition, it can enhance efficiency by either leveraging its established relationships or its experience with existing knowledge. Furthermore, by exploring in one domain and exploiting in the other such firm can attenuate certain types of risk and uncertainty associated with its alliance portfolio. It can decide whether to reduce technical risk in new technology development or rather avoid managerial challenges associated with ties to unfamiliar partners. The ability to decide in which domain to engage in exploration rather than exploitation supports the firm's efforts to specialize and thus improves the performance of its alliance portfolio. Therefore, a firm that balances exploration and exploitation across the function and structure domains can reduce risk and uncertainty while gaining efficiency and social capital which eventually contribute to firm performance (Baum, Calabrese, and Silverman 2000; Lee, Lee, and Pennings 2001).

Balancing exploration and exploitation across domains can not only provide important benefits but also eliminate certain organizational impediments associated with balance within domains. Assuming that 
the function and structure domains of alliance portfolios are independent, balancing exploration and exploitation across these domains enables a firm to attenuate inconsistency of behavioral patterns and avoid resource allocation tradeoffs that prevail when operating within a particular domain. Circumventing internal coordination of conflicting activities within each domain economizes on the firm's investments in distinctive partnering routines and facilitates the use of consistent routines for managing its alliances in each domain. Consequently, the firm can eliminate inherent tradeoffs and conflicts associated with reliance on inconsistent partnering routines. For example, a firm's practices for testing emerging technologies and assimilating partners' knowledge in the course of joint R\&D alliances do not counter the firm's investments in relation-specific assets, the development of interfirm trust, and the use of informal governance mechanisms, which are essential in repeated alliances with prior partners (Gulati 1995a). Hence, balance across domains enables the firm to simultaneously nurture organizational routines that regulate exploitation in one domain while supporting exploration in another (Lavie and Rosenkopf 2006). It enables the firm to overcome some organizational impediments that emerge when attempting to balance exploration and exploitation within domains while still enabling it to enjoy the benefits of balance in its alliance portfolio. Balancing exploration and exploitation across domains thus enhances firm performance. H2. Firm performance will be positively related to balance between exploration and exploitation across the function and structure domains of alliance formation decisions.

We have thus far argued that balancing exploration and exploitation within domains enables a firm to generate new sources of knowledge and social capital while leveraging existing knowledge and relationships. However, such balance entails tradeoffs in resource allocation and internal conflicts associated with the use of inconsistent organizational routines. Consequently, balance within domains should undermine firm performance whereas balance across domains, which circumvents these impediments, is expected to produce positive performance effects. In accordance with our conjectures, we would expect such performance implications to intensify as resource allocation tradeoffs and conflicting routines exacerbate. We argue next that these tradeoffs and conflicting routines exacerbate as the firm grows in size, thus making the balance within domains less beneficial whereas the performance 
implications of balance across domains become more favorable.

First, balancing exploration and exploitation within domains creates escalating resource allocation tradeoffs as a firm grows in size. At first glance, it may seem that a growing firm becomes less sensitive to resource allocation constraints (Lin et al., 2007); however, the availability of internal resources makes such firm less dependent on alliances as a primary source of resources (Lavie 2006). Specifically, smaller firm size implies limited reliance on internal value chain activities and greater dependence on alliance partners for both exploratory $R \& D$ activities and exploitative marketing or production activities. The ability to create social capital by maintaining both new and established relationships with partners is more central to a firm's reputation and eventual performance when it possess limited assets (Gulati and Higgins 2003; Stuart, Hoang, and Hybels 1999). As the firm grows in size it becomes more self-reliant and better able to carry out its internal operations, so that it is less vested in its alliance portfolio and less dependent on its alliance partners for furnishing network resources. An increase in firm size represents investments in assets owned by the firm's internal organization, which could limit the availability of resources for supporting external collaborative engagements. Hence, the accumulation of internal assets may undermine the vitality of the alliance portfolio, thus exacerbating resource allocation tradeoffs in the portfolio. In particular, competition for resources that support both exploration and exploitation within the function or structure domains intensifies when a firm owns a rich resource base that can serve for carrying out these activities internally rather than through alliances. Therefore, balance within alliance domains imposes increasing challenges as the firm grows in size.

Second, organizational routines that support opposing tendencies to explore versus exploit become pervasive as a firm grows in size, which results in organizational tension. A small firm size enables flexibility and better responsiveness when attempting to fine-tune exploration and exploitation efforts, but as the firm grows in size it may face stronger inertia (Hannan and Freeman 1984) and encounter reorganization challenges in the presence of conflicting partnering procedures. Given its enhanced flexibility, a small firm is sufficiently agile to transition between R\&D alliances and production or marketing alliances or to juggle new and existing partners, but as it grows in size it tends to be more 
bureaucratic and captive to its formal procedures (Child 1972), thus less flexible in modifying the composition of alliances in its portfolio. As the scale of its operations increases, the firm tends to rely on more formal procedures for carrying out partnering activities (Kale et al. 2002), and as a result, may find it more difficult to maintain inconsistent organizational procedures for simultaneously managing diverse types of alliances. The firm's exploration and exploitation routines are likely to become rigid and thus generate tension and conflict as it strives toward balance within domains. With growing size, the firm may face stronger inertial pressures when employing different procedures or adjusting its routines for collaborating with new versus familiar partners or when engaging in $R \& D$ versus marketing or production alliances. Consequently, balancing exploration and exploitation within domains entails increasing friction. Resource allocation tradeoffs and routine rigidity that intensify with firm size increase the costs of maintaining a balance within the function and structure domains and impair the firm's ability to effectively balance exploration and exploitation within these domains.

Finally, in light of the inertial pressures that increase with firm size, a firm can benefit more from specializing in either exploration or exploitation within a given domain. As the firm grows in size it is inclined to invest in fixed assets and specialized personnel. Such large investments in specialized assets and the increasing formalization of administrative structure and operating procedures inhibit further adaptation (Hannan and Freeman 1977; Nickerson and Silverman 2003). As it gains in size, the firm's heuristics give way to institutionalized rules and regulations that reinforce organizational routines (Nelson and Winter 1982). Consequently, increases in firm size limit the effectiveness of accommodating conflicting partnering routines. Nevertheless, as its size increases the firm can mitigate the organizational costs of balancing exploration and exploitation within domains by exploring in one domain while exploiting in another. For example, it can better benefit from engaging in recurrent alliances with partners that infuse new technologies, thus balancing function exploration with structure exploitation. Under such conditions, the firm is expected to gain increasing returns on specialization in either exploration or exploitation within each domain. Hence, a firm that attempts to balance activities across domains can enjoy the complementary benefits of exploration and exploitation while minimizing its reliance on 
conflicting organizational procedures and mitigating the administrative costs that accumulate with firm size. As its partnering routines become more rigid and prohibit effective balance of exploration and exploitation within domains, balancing across domains becomes a more viable approach for a firm that gains in size. Despite its increasing size, the firm can avoid the rising costs of reconciling conflicting procedures within domains and benefit more from balance across domains of its alliance portfolio.

H3. The negative associations between firm performance and balance within (a) the function domain and (b) the structure domain will intensify with increases in firm size.

H4. The positive association between balance across domains and firm performance will intensify with increases in firm size.

\section{Methods}

\section{Research setting and sample}

We tested our hypotheses using pooled time-series analysis of U.S.-based firms in the software industry (SICs 7371 through 7374). The dynamic and intensive formation of alliances in this industry enhances the meaningfulness, reliability, and variance of our variables. Our interviews with industry experts suggest that firms in this industry derive $30 \%-40 \%$ of their revenues from alliances, higher than the $26 \%$ revenue contribution reported in an Andersen survey of Fortune 500 firms (Kalmbach and Roussel 1999). Thus, alliances can meaningfully impact corporate performance in this industry. Moreover, the software industry features a high proportion of publicly traded firms, ensuring the accessibility of financial information and reducing potential size- and age-related biases. In addition, our sample is representative, since the worldwide software industry is dominated by U.S.-based firms. For instance, a Standard \& Poor's survey indicated that 23 of the top 25 software vendors are based in the United States, with U.S.based software firms accounting for half of the worldwide software market (Rudy 2000). ${ }^{2}$

This study's timeframe spanned 1990 to 2002, with historical alliances tracked back to 1985 in order to incorporate information on active alliances that were formed before 1990. This five-year window follows standard assumptions regarding the duration of alliances (Stuart 2000), which in our sample was

\footnotetext{
${ }^{2}$ Most of the focal firms were single business firms. Specifically, $84 \%$ of the firms had only a primary SIC code $10 \%$ had a single secondary SIC code, $5 \%$ had two secondary SIC codes, and less than $1 \%$ had three or four secondary SIC codes. Thus, it is appropriate to define the industry based on the primary SIC code.
} 
shorter than five years (1.767 years on average). The initial sample included all 367 U.S.-based publicly traded software firms that were active in the year 2001, had at least five years of records in the Compustat database, and engaged in at least one alliance during the study's timeframe. ${ }^{3}$ The effective sample size ranged between 320 and 339 firms because of the lag structure of our data, missing values, ${ }^{4}$ and the minimum number of observations per firm needed for computing the structure exploration variable.

Alliance records first were compiled from the SDC database and then extracted from alliance announcements and status reports in press releases and partner listings posted on the Factiva database, corporate websites, and Edgar SEC filings. Most announcements were cross-validated by at least two independent sources. The original press announcement served as the primary source of information for coding purposes. By relying on multiple sources and tracking follow-up announcements and status reports, we minimized the recording of alliances that were announced but not realized. To further validate our data, we reviewed some of our alliance listings with a select group of corporate executives in charge of alliances. Following these procedures, alliance records were corroborated, corrected, added, or eliminated. In total, we identified 20,779 alliances involving 8,801 unique partners from various industries. ${ }^{5}$ For each alliance we coded the announcement date, pre-specified duration or termination date, ${ }^{6}$ number of partners,

\footnotetext{
${ }^{3}$ We determined that the focus on U.S.-based firms that were active in 2001 and had at least five Compustat records is not likely to introduce a selection bias based on the lack of differences between the sampled firms and the remaining 297 publicly traded firms in the industry in terms of total assets $(t=1.43, p=.15)$, revenues $(t=0.53, p=$ $.60)$, number of employees $(t=0.27, p=.79)$, net income $(t=1.48, p=.14)$, cash $(t=1.51, p=.13)$, long-term debt $(t=0.07, p=.95)$, stock price $(t=1.27, p=.20)$, and other relevant measures. These results suggest that our sample is representative of public firms in the software industry.

${ }^{4}$ Missing values occurred in several variables. For instance, information on R\&D investments was missing for many firms that were not required to report these figures by SEC regulations.

${ }^{5}$ Only $24.7 \%$ of the identified alliances were reported in the SDC database. When comparing the proportions of different types of alliance agreements in our final database to those reported in SDC, we found that our data offers more extensive coverage of non-equity alliances $(t=25.85, p<0.001)$ and alliances with foreign partners $(t=25.73$, $p<0.001)$. The proportions of marketing $(t=34.36, p<0.001)$, original equipment manufacturing (OEM) $(t=$ $22.89, p<0.001)$, and $\mathrm{R} \& \mathrm{D}(t=36.17, p<0.001)$ agreements are also higher than in SDC, but the proportions of supply $(t=-4.16, p<0.001)$, licensing $(t=-26.87, p<0.001)$, and royalties $(t=-2.03, p<0.05)$ agreements are lower. These results rule out the possibility that the SDC database covers more substantial types of alliances.

${ }^{6}$ Alliance termination dates were unavailable for many alliances, because firms rarely announce alliance termination and occasionally maintain inactive alliances. If the date of alliance termination was unavailable from archival sources, when possible it was calculated based on alliance extension announcements and reports of active alliance status in a given year. For example, an alliance partner that was mentioned in a press release, in a 10K SEC form, or in listings of partners posted on the firm's corporate website was coded as active during the year in which such report was found. Alliance termination dates were available for $23 \%$ of the alliances. Remaining alliances were assumed to have a three-year duration based on the average specified duration of other alliances in the sample as
} 
and partners' identities and countries of origin, as well as the strategic significance of the alliance, whether it was a joint venture, and its classification to categories of agreements: R\&D, production, marketing and service, original equipment manufacturing / value-added resale, licensing, royalties, or supply. An alliance could involve more than one type of agreement. Edgar SEC files served for determining firms' year of incorporation. Additional firm-specific data, such as total assets, revenues, long-term debt, cash, R\&D expenses, and net income, were extracted on an annual basis from Compustat. Data on common shares outstanding and stock prices were gathered from the Compustat-CRSP database. The firm-year served as the unit of analysis because the dependent variables were defined at the firm level. The data for the 20,779 alliances were transformed to 2,587 firm-year observations corresponding to the years 1990-2001 by pooling the data for all alliances in a firm's portfolio in a given year. The effective sample size in multivariate analysis ranged between 1,651 and 2,072 observations.

\section{Variables}

Dependent variables - firm performance. According to March, no single performance measure can fully capture the benefits of exploration and exploitation: "returns from exploration are systematically less certain, more remote in time.... What is good in the long run is not always good in the short run" (1991: 73). Thus, to avoid possible bias in measuring the outcomes of exploration versus exploitation, we used two performance measures: net profit as a short-term performance measure (Narayanan 1985) and firm market value as a long-term performance measure (Kale, Dyer, and Singh 2002). Net profit is considered an accounting measure of financial performance (Barnett, Greve, and Park 1994; Brush, Bromiley, and Hendrickx 2000), whereas market value represents investors' ex ante expectations about firms' future market performance (Lubatkin and Shrieves 1986). Market value was calculated by multiplying the firm's stock price by the number of common shares outstanding. Due to the high volatility of this measure, the annual market value was calculated by averaging the 12 end-of-month daily values of the relevant

well as assessments of industry experts. The imputation of alliance termination dates is a common practice in alliance research. For example, Stuart (2000) imputed alliance duration for all alliances using a linear depreciating weighting for alliances with an earlier date of formation. In our study, the use of imputation was reduced by searching alliance status reports and recording alliance termination dates when available. We controlled for the implications of this imputation procedure by including a separate control for the average age of alliances. 
calendar year. We lagged all the explanatory variables and controls in the performance model by one year relative to the dependent variables in order to facilitate causal interpretation of our findings.

Function exploration. We operationalized exploration-exploitation with a combined continuous measure (Lavie and Rosenkopf 2006) rather than with two separate indicators under the assumption that exploration inhibits exploitation and vice versa, so that these two activities conflict (Abernathy 1978; March 1991). This assumption is consistent with the negative correlation that we observed between upstream and downstream alliance formation in the function domain $(r=-.710, p<.001)$. We followed Koza and Lewin's (2000) distinction between exploration, exploitation, and hybrid alliances that integrate downstream and upstream activities. Based on alliance announcements, a categorical indicator denoted for each alliance whether it involved a knowledge-generating R\&D agreement (coded "1"), another type of agreement based on existing knowledge involving joint marketing and service, OEM/VAR, licensing, production, or supply (coded “ 0 ”), or a combination of R\&D and other agreements (coded " 0.5 "). Unlike internal $R \& D$ that draws directly from the firm's existing knowledge, $R \& D$ agreements in the software industry entail moving outside of the firm's technical knowledge base or at least integrating internal knowledge with external knowledge of partners, thus representing exploration. Our function exploration measure was calculated as the average value of the alliance agreement indicator across all alliances formed by the focal firm in year $t$. Values range from 0 to 1 , with high values indicating function exploration and low values indicating function exploitation.

Structure exploration. For each alliance formed by the focal firm, an indicator received a value of "1" if the firm had no joint prior alliances with its partner and " 0 " if such alliances existed. Then, for each firm, structure exploration was calculated as the average value of this indicator across all alliances formed by that firm in year $t$. In order not to classify a firm's first alliance as structure exploration by default, for lack of prior partnering history, we excluded 181 firm-year observations corresponding to years in which firms formed their first and only alliance. Auxiliary analysis revealed, however, that our findings remain virtually unchanged when these observations are retained. Values range from 0 to 1 , with high values indicating structure exploration and low values indicating structure exploitation. 
Firm size. We measured firm size as the value of total assets reported in Compustat. Firm size served as a moderator of the relationship between exploration-exploitation and firm performance per hypotheses 3 and 4. This measure was highly correlated with alternative measures based on firm revenues $(r=.840, p$ $<.001)$ and firm equity $(r=.850, p<.001)$. We did not consider the number of employees given that the industry is not labor intensive. Robustness tests using the alternative measures produced consistent results. Control variables. We controlled for inter-industry variation by studying a single industry. ${ }^{7}$ In addition, our controls included annually updated firm- and portfolio-level variables that were lagged by one year relative to the dependent variables. Firm-level controls included firm size as measured by the value of total assets, firm R\&D intensity as measured by R\&D investments divided by revenues, and firm solvency as measured by the log-transformed ratio of cash to long-term debt. The firm's available slack as captured by the solvency measure and its internal investment in R\&D may be indicative of the firm's tendency to engage in internal exploration efforts. The firm's R\&D intensity further controls for the extent to which the firm invests in completely new technologies versus ones with which it has some prior experience (Christensen 1998). We also included a measure of the firm's number of acquisitions in a given year since acquisitions may serve as an alternative mode for undertaking exploration outside the firm's boundaries (Schilling and Steensema 2002). Portfolio-level controls included the adjusted size of the alliance portfolio (Ahuja 2000; Baum et al. 2000; Stuart et al. 1999), calculated as the logarithm of the number of alliances divided by the firm's total assets. The size of the alliance portfolio may be related to the firm's investments in searching for partners and governing its alliances. Multi-partner alliances were decomposed to dyads for the purpose of calculating this control variable, which captures the firm's propensity to form alliances. Hence, we also controlled for the average number of partners involved in each alliance. Following prior research (Contractor, Kundu, and Hsu 2003; Lavie and Miller, 2008), we controlled for the proportion of foreign partners in the alliance portfolio. To control for changes in the contributions of alliances as they progress, we measured the average age of alliances in the portfolio. We

\footnotetext{
${ }^{7}$ An indicator of the firm's four-digit SIC segment was not included as a control variable because of redundancy and the occurrence of complete separation when the firm fixed effects were also included in the tested models.
} 
controlled for the complexity of alliances in the portfolio by including a measure of the proportion of different agreement types per alliance. In addition, we included a measure of the percentage of equity joint ventures in the alliance portfolio to control for the alliance governance structure. The strategic significance of alliances was controlled by measuring the percentage of alliances that were identified as strategic in alliance announcements. By measuring the duration, complexity, governance, and importance of alliance relationships we control for relational embeddedness in the alliance portfolio (Uzzi 1996). This set of controls helped us discern the performance effects of exploration and exploitation from the implications of other properties of the firm's alliance portfolio. All remaining inter-temporal trends and interfirm heterogeneity were controlled for with firm fixed effects and year dummy indicators. ${ }^{8}$

\section{Analysis}

Table 1 provides descriptive statistics. We used two-stage analysis for handling potential endogeneity in firms' decisions to engage in exploration and exploitation in their alliances (Lavie and Rosenkopf 2006). Firms' tendencies to explore or exploit may derive from managers' performance expectations based on firm attributes and industry conditions. Failing to account for such endogeneity may bias the estimates of exploration-exploitation effects and lead to erroneous conclusions (Hamilton and Nickerson 2003). The specification and results of our first-stage models are reported in the Appendix. The predicted values of function exploration and structure exploration from the first-stage models were entered as independent variables in the second-stage models, where the firm's market value and net profit served as dependent variables. We implemented our second-stage models using cross-section time-series regressions with firm fixed effects. Fixed effects models control for unobserved heterogeneity in the form of time-invariant variables and in our case were found to be equivalent or superior to random effects models based on Hausman (1978) tests. The inclusion of firm fixed effects suggests that the reported models explain within-firm variation in performance over time rather than interfirm variation in performance. In addition,

\footnotetext{
${ }^{8}$ In auxiliary analyses we considered additional control variables which were not reported eventually. For example, we accounted for synergetic portfolio effects due to overlap in partners' businesses (Vassolo, Anand, and Folta 2004). For each firm we calculated the number of partners with the same primary SIC code averaged across all unique SIC codes of partners in the firm's alliance portfolio in a given year. This control variable produced positive yet insignificant effect on firm performance without affecting our reported results.
} 
the analysis of panel data raises concerns about serial correlation of errors within cross-sections, which may deflate standard errors and inflate significance levels. Indeed, Baltagi-Wu (1999) locally best invariant (LBI) test for autocorrelation detected first-order autocorrelation in market value $(L B I=1.366)$ and net profit $(L B I=1.444)$. Autocorrelation was treated by incorporating first-order autoregressive errors in the tested models, assuming correlation of errors across adjacent years. ${ }^{9}$ Thus, the tested models took the form: $\boldsymbol{y}_{i, t+1}=\alpha+\beta \boldsymbol{x}_{i, t}+u_{i}+\varepsilon_{i, t}$, where $\varepsilon_{i, t}=\rho \varepsilon_{i, t-1}+\mu_{i, t}$ and $-1<\rho<1$. In this equation, $u_{i}$ represents the firm fixed effects and $\rho$ is the autoregressive $\operatorname{AR}(1)$ parameter, which has a zero mean, homoskedastic, and serially uncorrelated error term $\mu_{i, t}$. We subjected these models to maximum likelihood estimation, treating missing values with listwise deletion.

We relied on partial models for testing our hypotheses since tests for potential multicollinearity indicated that the maximum VIF index in the full models exceeded the critical value of 10 (Kleinbaum, Lawrence, Muller, and Nizam 1998). The high VIF values can be ascribed to the multiple instances of the function exploration and structure exploration variables and the firm size moderator. Still, VIF values dropped significantly and no symptoms of multicollinearity were present (Maddala 2001) in Models 4 and 9, which simultaneously incorporated the effects of function exploration and structure exploration. We evaluated the fit of our models with log likelihood ratio tests comparing each model to the baseline model (Model 1) after adjusting for the number of observations discarded because of missing values.

\section{Insert Tables $1-4$ about here}

\section{Results}

Tables 2-3 and 4 correspondingly report the results of hierarchical second-stage models for balance within domains and balance across domains. Since we run parallel analyses for each dependent variable, we use the subscripts "MV" and "NP" to connote models for market value and net profit respectively. Models $1_{\mathrm{MV}}$ and $1_{\mathrm{NP}}$ are baseline models that include the control variables. Hypotheses $1 \mathrm{a}-\mathrm{b}$ predicted negative performance implications of balance within (a) the function domain (tested with Models $2_{\mathrm{MV}}$ and $2_{\mathrm{NP}}$ ) and

\footnotetext{
${ }^{9}$ Potential contemporaneous (cross-sectional) correlation across firms in the panel data was also tested and ruled out since the additional covariance parameter turned out to be insignificant.
} 
(b) the structure domain (tested with Models $3_{\mathrm{MV}}$ and $3_{\mathrm{NP}}$ ). A negative linear term of the exploration variable and a positive quadratic term in these models would suggest a U-shaped curve in support of this set of hypotheses. Even though the coefficients had the expected signs, Models $2_{\mathrm{MV}}$ and $2_{\mathrm{NP}}$ indicate no significant effects of balance within the function domain on either market value or net profit, with the exception of a significant positive effect of the quadratic term of function exploration on firm market value $(\beta=18.37, p<.05)$. This finding does not support the premise that balance within the function domain has favorable performance implications. Instead, excessive exploration in that domain contributes to superior market value. ${ }^{10}$ Model $3_{\mathrm{Mv}}$ reveals a negative effect of structure exploration $(\beta=-152.1, p$ $<.001)$ and a positive effect of its quadratic term on market value $(\beta=85.38, p<.001)$. Similarly, Model $3_{\mathrm{NP}}$ reports a negative effect of structure exploration $(\beta=-5.348, p<.01)$ and a positive effect of its quadratic term on net profit $(\beta=3.154, p<.01)$. These U-shaped patterns of structure exploration are consistent with hypothesis $1 \mathrm{~b}$. These results remain significant when testing the effects of function exploration and structure exploration simultaneously in Models $4_{\mathrm{MV}}$ and $4_{\mathrm{NP}}$.

Hypotheses $3 a-b$ predicted that the negative performance implications of balance within (a) the function domain (tested with Models $5_{\mathrm{MV}}$ and $5_{\mathrm{NP}}$ ) and (b) the structure domain (tested with Models $6_{\mathrm{MV}}$ and $\left.6_{\mathrm{NP}}\right)$ will intensify with increases in firm size. These hypotheses are supported if the performance function becomes more concave (U-shaped as opposed to inverted U-shaped) when the exploration variables are moderated by firm size. In support of hypothesis $3 \mathrm{a}$, Model $5_{\mathrm{MV}}$ (Table 2 ) reveals a positive effect of function exploration on market value $(\beta=21.69, p<.001)$ and a negative effect of its quadratic term $(\beta=-24.09, p<.001)$. In turn, the interaction effect of firm size and function exploration on market value is negative $(\beta=-110.5, p<.001)$, while the interaction of firm size and the quadratic term of function exploration is positive $(\beta=136.17, p<.001)$. Similarly, Model $5_{\mathrm{NP}}$ (Table 3$)$ indicates a positive linear effect $(\beta=1.552, p<.001)$ and a negative quadratic effect $(\beta=-1.464, p<.001)$ of function

\footnotetext{
${ }^{10}$ In auxiliary analysis we dropped the quadratic term from Model $2_{\mathrm{MV}}$. The difference in fit statistics between the reported model and the linear model was significant $(\Delta-2 \mathrm{LL}=5.1, \mathrm{p}<0.05)$. We thus conclude that even though the linear term in Model $2_{\mathrm{MV}}$ is insignificant, the curvilinear function better fits the data than a linear function, in accordance with Hypothesis $1_{\mathrm{MV}}$.
} 
exploration on net profit. The interaction of firm size with the linear term of function exploration is negative $(\beta=-6.433, p<.001)$, while its interaction with the quadratic term of function exploration is positive $(\beta=6.624, p<.001)$. These findings demonstrate how the effects of function exploration on market value and net profit shift from inverted U-shaped to U-shaped with increases in firm size.

Similarly, Model $6_{\mathrm{MV}}($ Table 2$)$ reveals a positive linear effect $(\beta=165.5, p<.001)$ and a negative quadratic effect $(\beta=-95.74, p<.001)$ of structure exploration on market value. The interaction of firm size with the linear term of structure exploration is negative $(\beta=-311.6, p<.001)$, while its interaction with the quadratic term is positive $(\beta=170.2, p<0.01)$. In Model $7_{\mathrm{NP}}$ (Table 3$)$ the linear effect of structure exploration on net profit is positive $(\beta=3.873, p<.05)$, whereas the effect of its quadratic term is negative $(\beta=-2.215, p<.1)$. The interaction effect of firm size with the linear term of structure exploration is negative $(\beta=-13.71, p<.001)$, whereas its interaction with the quadratic term is positive $(\beta$ $=7.944, p<.001)$. Hence, these findings reveal how the effects of structure exploration on market value and net profit shift from inverted U-shaped to U-shaped with increases in firm size in accordance with hypothesis $3 b$. The interaction effects of firm size with the function and structure exploration functions remain significant when introduced simultaneously in Models $7_{\mathrm{MV}}$ and $7_{\mathrm{NP}}$. Figure 1 depicts the predicted performance functions for balance within domains. This figure reaffirms the U-shaped effects of balance within the function and structure domains, revealing modest superiority of function exploration and a major advantage of structure exploitation, as firms grow in size.

Table 4 reports the results of models used for testing hypotheses 2 and 4 on the performance implications of balance across domains. In particular, Models $9_{\mathrm{MV}}$ and $9_{\mathrm{NP}}$ serve to test hypothesis 2 by introducing a linear interaction of function exploration and structure exploration. Positive main effects and negative interaction effects would suggest that simultaneous increases in exploration in both domains are not beneficial, as predicted by this hypothesis. Accordingly, when exploration is extensive in one domain and limited in the other, firm performance should improve. Indeed, these models reveal positive effects of function exploration on market value $(\beta=84.47, p<.001)$ and net profit $(\beta=2.86, p<.01)$ as well as positive effects of structure exploration on market value $(\beta=30.83, p<.05)$ and net profit $(\beta=$ 
$1.276, p<.1)$. Yet, the interaction effects of function exploration and structure exploration are negative for both market value $(\beta=-84.3, p<.001)$ and net profit $(\beta=-2.928, p<.05)$. In support of hypothesis 2 , these findings suggest that when a firm increases exploration in either the function or the structure domain, its performance improves, but when exploration increases in both domains it faces decline in performance.

Finally, Models $10_{\mathrm{MV}}$ and $10_{\mathrm{NP}}$ serve to test hypothesis 4 which suggested intensifying positive effects of balance across domains as firms gain in size. These models supplement Models $9_{\mathrm{MV}}$ and $9_{\mathrm{NP}}$ by introducing interaction terms for its covariates with firm size. Hypothesis 4 gains support to the extent that the moderated effects reinforce those tested by Models $9_{\mathrm{MV}}$ and $9_{\mathrm{NP}}$, i.e. positive interactions of firm size with function exploration and structure exploration as well as a negative three-way interaction of firm size with function exploration and structure exploration. Indeed, Model $10_{\mathrm{MV}}$ provides such support with positive interaction effects of firm size with function exploration $(\beta=170.07, p<.001)$ and structure exploration $(\beta=78.66, p<.001)$ and a negative three-way interaction effect on market value $(\beta=-188.7$, $p<.001)$. Similarly, Model $10_{\mathrm{NP}}$ offers support to hypothesis 4 with positive interaction effects of firm size with function exploration $(\beta=6.314, p<.001)$ and structure exploration $(\beta=3.074, p<.001)$ and a negative three-way interaction effect on net profit $(\beta=-8.277, p<.001) .{ }^{11}$ Thus, the negative effect of the interaction between function exploration and structure exploration on net profit intensifies with firm size. Figure 2 shows favorable performance implications of balance across domains for a mean-sized firm, especially for a configuration of function exploration and structure exploitation. The benefits of balance across domains intensify with increases in firm size, but at very small firm sizes, balance across domains produces unfavorable performance implications. Our results are summarized in Table 5.

\section{Robustness Tests}

Insert Table 5 about here

\footnotetext{
${ }^{11}$ The multiple inclusions of the exploration variables and the moderator in these models resulted in high VIFs (reaching 34.78 in Model $10_{\mathrm{MV}}$ and 34.56 in Model $10_{\mathrm{NP}}$ ). However, with the exception of insignificant unmoderated terms of function and structure exploration in Model $10_{\mathrm{NP}}$, no symptoms of multicollinearity were observed and the exclusion of the interaction terms of firm size with the exploration variables, while significantly reducing VIF levels, retained the negative effects of the three-way interactions. Furthermore, our models produced consistent results after dropping insignificant controls such as firm R\&D intensity, firm solvency, alliance age, agreements per alliance, and percentage of foreign partners, thus attenuating concerns of multicollinearity.
} 
To test the robustness of our findings we first considered alternative operationalizations of firm performance. This auxiliary analysis revealed that hypothesis 1 gained support with respect to function exploration when firm performance was measured as growth in market value and with respect to structure exploration when firm performance was measured as growth in net profit. Hypothesis 2 gained support when growth in net profit or exponential growth in market value served as an alternative performance measure. Additionally, hypotheses 3 and 4 gained support when growth in market value was used as the dependent variable. Nevertheless, our reported measures of firm performance (market value and net profit) were more consistent. Additionally, our results were robust to the inclusion of net profit as a control variable when testing market value models and vice versa. Moreover, we tested the robustness of incorporating one-year lag between exploration activities and our performance measures by considering models in which we introduced two- and three-year lags. Our results revealed that models with one-year lag produced better fit statistics, thus reaffirming our model specification. Furthermore, we considered the possibility that different types of alliances produce outcomes at different stages of their lifecycles by incorporating an interaction of alliance age with function exploration in our models. This term turned out insignificant and did not influence the significance of our predicted effects.

Next, we considered a firm's revenues as an alternative measure of the size moderator, finding that our results remained significant with the exception of the unmoderated effects of function exploration and structure exploration on net profit in Models $5_{\mathrm{NP}}-7_{\mathrm{NP}}$, the main effect of structure exploration on net profit in Model $9_{\mathrm{MV}}$, and the main effects and interaction of function exploration and structure exploration on net profit in Models $9_{\mathrm{NP}}$ and $10_{\mathrm{NP}}$. We then considered the possibility that our moderator captures the effect of the size of the firm's alliance portfolio. When we replaced the firm size moderator with a measure of the number of partners in the firm's alliance portfolio, hypotheses 3 and 4 gained support, which is understandable given the high correlation between the number of partners and the firm's asset value $(r=.740, p<.001)$ and revenues $(r=.520, p<.001)$. To isolate our moderation effect we tested revised models in which both firm size and the size of the alliance portfolio were introduced as moderators. In these models the moderation effects of firm size retained their levels of significance, 
whereas the moderation effects of the size of the alliance portfolio became inconsistent or insignificant with the exception of the effect on the association between balance in the structure domain and the firm's market value. Similarly, when firm age was used as a moderator instead of firm size, hypotheses 3 and 4 gained partial support with insignificant interaction effect of firm age and function exploration on market value. When the firm age moderator was incorporated together with the firm size moderator, the interactions involving firm size remained significant whereas the interactions with firm age lost significance or became inconsistent due to suspected multicollinearity. These auxiliary analyses reaffirm our choice of firm size as a moderator. ${ }^{12}$

In addition, we considered second-order exploitation (Lavie and Rosenkopf 2006), whereby prior exploration experience in a particular domain may help some firms enhance the effectiveness of subsequent exploration efforts in that domain. We tested the effects of exploration in the function and structure domains moderated by prior exploration experience in the corresponding domain. The moderation effects of prior experience in the function domain were insignificant but the interaction of structure exploration and prior exploration experience had a positive effect on market value (the main effect was negative). A similar pattern was observed with net profit as the dependent variable, although the moderation effect was only marginally significant. Thus, gaining experience in forming alliances with new partners enables the firm to enhance the contribution of such alliances to its performance. Accordingly, the benefits of exploration and exploitation may be idiosyncratic and depend on the firm's particular exploration experience in certain domains.

\section{Discussion}

Following March (1991), scholars have advocated the balance between exploration and exploitation yet acknowledged the challenges that firms may face when pursuing such balance (Gupta et al. 2006). Organizational and temporal separation have been offered as a means for simultaneously exploring and

\footnotetext{
${ }^{12}$ The partially significant moderation effects of firm age and the size of the alliance portfolio are consistent with our theory, since resource allocation constraints and conflicting organizational routines can result not only from the impediments associated with a large organization but also from the rigidities ascribed to maturation and increases in the number of alliances in the portfolio. Yet, resource allocation constraints may be less prevalent in the latter cases.
} 
exploiting (Brown and Eisenhardt 1997; Tushman et al. 1997), yet limited systematic evidence exists concerning the performance implications of balance between these two organizational activities. We advance an emerging stream of research on exploration and exploitation in alliances (Beckman et al. 2004; Koza and Lewin 1998; Lavie and Rosenkopf 2006; Lin et al. 2007; Park et al. 2002; Rothaermel 2001; Rothaermel and Deeds 2004) by examining the performance implications of balance within and across domains of alliance formation. Our findings reveal that the traditional form of balance within the function and structure domains is disadvantageous whereas balance across the function and structure domains can contribute to firm performance. We also identify heterogeneity in firms' abilities to benefit from balance within and across domains. Hence, we divert attention from the basic question of whether a balance between exploration and exploitation is desirable to focus on the means by which firms can best leverage different forms of balance in their alliance formation decisions.

Our framework complements the organizational and temporal separation approaches by underscoring the merits of balancing exploration and exploitation across domains as opposed to balance within domains. In fact, the traditional approach to the ambidexterity problem (Tushman and O'Reilly 1996) can be considered a special case of our framework whereby the firm balances exploration and exploitation within a single domain by allocating technological activities to separate organizational units. According to Benner and Tushman, "ambidextrous organizations are composed of multiple tightly coupled subunits that are themselves loosely coupled with each other. Within subunits the tasks, culture, individuals, and organizational arrangements are consistent, but across subunits tasks and cultures are inconsistent and loosely coupled" (2003: 247). The main difference between such organizational separation and our approach is that in the case of alliances, separation takes place across domains of the alliance portfolio rather than across organizational units. Indeed, a firm's use of alliances for exploration or exploitation may entail separation between internal organizational units that pursue one type of activity from alliances that serve to carry out the other. Nevertheless, since in most cases alliances serve to both explore and exploit, domain separation is not equivalent to organizational separation. Even when a firm establishes a dedicated alliance function, such a corporate unit is responsible for all types of alliances regardless of the 
function that they serve or the incumbency status of partners in the alliance portfolio.

\section{Resolving the exploration-exploitation dilemma in alliance portfolios}

Traditionally, research on exploration and exploitation has limited its focus to balance within a single domain, such as in the case of technology versus marketing and production alliances in the function domain (Rothaermel and Deeds 2004) or new versus prior partners in the structure domain (Lin et al. 2007). Our study demonstrates that this form of balance within domains contributes to financial performance neither in the short term nor in the long term. In particular, a firm does not benefit from simultaneously leveraging its alliances to generate new knowledge and to utilize existing knowledge. Furthermore, in line with prior research (Lin et al. 2007), a firm that simultaneously invests in seeking new partners and renewing existing alliance relationships can expect decline in its market value and net profit. We ascribe this performance decline to resource allocation tradeoffs and inconsistent partnering routines that offset the benefits of simultaneously extending the reach and receptivity to network resources. The inability to develop and employ consistent partnering routines (Nelson and Winter 1982) and the misapplication of such routines (Jensen and Szulanski 2004; Lavie and Miller, 2008) result in negative learning effects that impede processes of forming, managing, and assessing alliances.

Furthermore, our findings reveal that the impediments associated with balance within domains exacerbate with firm size. In contrast to preliminary findings of prior research (Lin et al. 2007), we show that as a firm accumulates assets, balance within a domain incurs losses and decline in market value since the firm may lose flexibility and hence its ability to reconcile conflicting exploration and exploitation routines within a given domain. Besides routine rigidity, the firm may become less dependent on its alliances as it accumulates internal assets, which exacerbates resource allocation tradeoffs in the alliance portfolio and undermines performance. Firms that nurture extensive alliance portfolios often develop consistent partnering routines and attempt to coordinate their engagements in multiple alliances. Despite the immediate merits of such practices (Hoffmann 2007; Kale et al. 2002; Lavie 2007; Zollo et al. 2002), we caution that as a firm grows and perhaps extends its alliance portfolio, the difficulty of balancing exploration and exploitation within the function or structure domains can impair financial performance. 
Whereas balancing exploration and exploitation within domains does not lead to desirable performance, our findings underscore the merits of balance across domains. A firm can increase its profits and market value by exploring in one domain while exploiting in another, yet faces declining performance when attempting to simultaneously explore in both domains. This form of balance enhances both innovativeness and productivity without needing to reconcile conflicting partnering routines or coping with resource allocation tradeoffs within each domain. The firm can effectively discover new knowledge while leveraging its relational embeddedness with familiar partners or rather extend its network reach and social capital while leveraging its existing knowledge base. Attempts to simultaneously explore by initiating R\&D alliances while seeking new partners introduce undesirable managerial challenges, whereas attempts to simultaneously reinforce existing relationships while engaging in marketing and production alliances degenerate the alliance portfolio by restricting heterogeneity and access to technological opportunities. Consequently, a firm that balances exploration and exploitation across domains can more effectively reap the benefits of balance. Nevertheless, such a firm still faces the challenge of deciding whether to concentrate on exploration or exploitation in a given domain. Trial and error is not advisable since this approach may draw the firm toward balance within domains. A firm may need to identify its relative strengths within each domain, consider performance feedback, and examine the nature of partnering opportunities when deciding whether to explore or exploit in a given domain.

Furthermore, balancing exploration and exploitation across domains becomes a more attractive form of balance as a firm gains in size. A small firm cannot effectively leverage balance across domains, possibly due to the inability of its internal organization to complement alliance operations in a given domain. Despite its dependence on alliances, its challenge of attracting prominent partners may limit the prospects of specialization and exclusive reliance on alliances for either exploration or exploitation. Yet, as the firm grows, it faces more dominant resource allocation constraints in its alliance portfolio and its partnering routines are likely to become more rigid. Hence, a growing firm can gain more by specializing in either exploration or exploitation within a given domain. For such firm, balance across domains becomes a more efficient solution although it can also rely on organizational separation to support 
specialization. Hence, by discretionally manipulating exploration and exploitation tendencies within and across domains, firms can maximize the benefits of their alliance portfolios both in the short term and in the long term.

\section{Directions for future research}

This study contributes to understanding the conditions and means by which firms can benefit from balancing exploration and exploitation in their alliance portfolios, yet leaves room for future research. First, we have studied the function and structure domains following established research on alliances (e.g., Beckman, et al. 2004; Grant and Baden-Fuller 2004; Koza and Lewin 1998; Lin et al. 2007; Park et al. 2002; Rothaermel 2001). Future research may consider additional domains corresponding to the attributes of alliance partners, such as their industry focus (Lavie and Rosenkopf 2006). It may refine some domains, for instance, by studying the degree of technological innovation (Christensen 1998) promoted by alliances in the function domain instead of dichotomously categorizing alliances based on their value chain functions. It may be also worthwhile to examine exploration and exploitation in this domain based on the productive outcomes of upstream and downstream alliances. Additionally, future research may advance the ambidexterity literature by uncovering relevant domains of exploration and exploitation within a firm's organization, thus extending our approach to the intra-organizational context. We believe, however, that since our logic is not dependent on the nature of domain, consideration of additional domains is likely to produce consistent findings.

Second, our study complements prior research that has studied the balance between exploration and exploitation within organizational boundaries (Brown and Eisenhardt 1997; He and Wong 2004; Jansen, Van Den Bosch, and Volberda 2006; Sidhu et al. 2007; Tushman and O'Reilly 1996) by considering balance in alliances that transcend such boundaries. Besides balancing exploration and exploitation across domains in the firm's alliance portfolio, a firm can balance these activities across organizational boundaries, i.e., exploit internally while exploring through alliances or vice versa. It can also engage in acquisitions to facilitate its exploration or exploitation efforts. Such approaches can substitute the need for balance within the function or structure domains of the alliance portfolio. In the current study we sought 
to control for these alternative modes, but future research may directly investigate the performance implications of balance within and across organizational boundaries by simultaneously studying exploration via internal units, alliances, and acquisitions. Such research may identify additional tradeoffs and optimal policies for exploring and exploiting through various organizational modes.

Third, once scholars juxtapose exploration and exploitation tendencies within and across organizational boundaries they can effectively assess the advantages of domain separation compared to organizational separation and temporal separation. Domain separation may be superior yet accompanied by organizational separation or temporal separation which play a role in shaping organizational tradeoffs and nurturing exploration and exploitation routines. Nevertheless, studying organizational separation may require more intimate understanding of firms' organizational structures and the roles of their various units.

Fourth, future research may examine additional contingencies besides firm size that may shape the benefits of balancing exploration and exploitation within and across domains. For instance, recent research has underscored the role of environmental uncertainty, dynamism, and competitiveness (Jansen et al. 2006; Lin et al. 2007; Park et al. 2002), shedding some light on the interplay between internal and external drivers of exploration and exploitation effects. These drivers may shape the effects of balance within and across domains of the alliance portfolio. In addition, we underscore the role of routine rigidity and other organizational impediments that may steer a firm away from balance within domains. Perhaps future research can identify organizational forces that relieve firms from resource allocation tradeoffs and mitigate the costs of balance within domains. Interestingly, increases in firm size which make balance within domains less favorable in the alliance portfolio relax resource allocation constraints in the internal organization, and may thus enhance the benefits of balance within intra-organizational domains.

Finally, future research may test our framework in other industries. We have focused on the software industry, since its intensity of alliance formation enables us to effectively track patterns of exploration and exploitation. Resource allocation tradeoffs and inconsistent organizational routines may be more or less critical for firm performance in other industries. Furthermore, the optimal level of balance may vary across industries. For instance, in highly dynamic industries balance may be achieved at higher levels of 
exploration, whereas stable industries may favor higher levels of exploitation. Nevertheless, while firms in other industries may demonstrate different patterns within certain domains, we still expect that balance across domains will be more advantageous than balance within domains of the alliance portfolio.

This study makes important strides toward resolving the dilemma posed by March (1991). It furnishes evidence on the implications of balancing exploration and exploitation, revealing how they depend on the means by which firms pursue this balance and on their organizational characteristics. Whereas balance within alliance domains can be detrimental to firm performance, balancing exploration and exploitation across such domains serves as a beneficial approach. The ambidexterity literature, while acknowledging the challenge of reconciling conflicting organizational routines that support exploration versus exploitation, has called for organizational separation which in and of itself is difficult to develop and maintain. Our approach does not require the nurturing of inconsistent managerial practices at the corporate level, the hiring of nimble managers, the use of job rotation and other managerial techniques that impose their own organizational challenges. Rather, it entails recognizing the multidimensionality of the problem by looking at multiple organizational domains, thus enhancing firm performance without facing the adverse consequences of introducing organizational buffers or constantly modifying organizational structures, which is especially problematic for a firm that manages large-scale operations.

\section{Appendix - First Stage Model}

In this study we used a two-stage analysis to account for endogeneity in firms' tendencies to engage in exploration and exploitation. Specifically, firms' decisions to engage in exploration versus exploitation may change over time (Lavie and Rosenkopf 2006) or throughout product life cycles (Rothaermel and Deeds 2004). In addition, as firms mature they may become more dependent on their established routines and skills (Hannan and Freeman 1984) and thus less likely to change their strategic orientations (Kelly and Amburgey 1991) and engage in exploration. Prior research also suggests that tendencies to explore or exploit vary with firm size (Beckman et al. 2004; Rothaermel and Deeds 2004). Moreover, firms' external exploration activities through alliances may complement or substitute internal exploration activities. The 
availability of financial funds may further facilitate slack-induced search (Bourgeois 1981; Levinthal and March 1981; March 1976; Nohria and Gulati 1996). In turn, prior partnering experience has been associated with organizational inertia ( $\mathrm{Li}$ and Rowley 2002) and may account for path dependence in alliance formation decisions in the structure domain (Chung et al. 2000; Gulati and Gargiulo 1999). Finally, prior experience in exploring in the function or structure domains may influence future exploration tendencies in the corresponding domain (Lavie and Rosenkopf 2006).

Therefore, in the first-stage models we regressed function exploration and structure exploration at time $t$ on a firm's age, size, R\&D intensity, financial solvency, partnering experience, and exploration experience in the corresponding domain at time $t$-1. Prior partnering experience was computed as a count of all prior alliances formed by the focal firm with any partner between 1985 and the preceding year. Exploration experience was calculated with the same formulas used for constructing our exploration measures, but instead of incorporating the alliances formed in year $t$ we counted alliances between 1985 and the preceding year $(t-1)$. All the independent variables in the first-stage model were lagged by one year relative to the dependent variables with the exception of firm age, which was time-invariant given the inclusion of year fixed effects. All remaining interfirm heterogeneity in exploration-exploitation was controlled for by firm fixed effects. The combination of year and firm fixed effects in addition to the prior history of exploration experience effectively accounts for unobserved heterogeneity (Blundell et al. 1995). The first-stage Tobit model (Tobin 1958) reported in Table 6 was estimated using maximum likelihood estimation while accounting for the panel structure of the data and correcting for autocorrelation using first-order AR(1) process. The values of the dependent variables were forced to range between 0 and 1 .

\section{Insert Table 6 about here}

Table 6 reports the results of the first-stage model, predicting function exploration and structure exploration in alliances. The results reveal that prior partnering experience facilitates exploitation in the structure domain $(\beta=-0.001, p<.05)$, consistent with prior research that shows how extensive partnering experience encourages firms to seek prior partners for their new alliances (Beckman et al. 2004; Lavie and Rosenkopf 2006). Additionally, exploration in both the function and structure domains was 
negatively related to prior experience in the corresponding domain $(\beta=-0.259 ; \beta=-0.601, p<.001)$. Most of the variance in function exploration and structure exploration can be ascribed to prior experience as well as to the firm and year fixed effects that capture unobserved heterogeneity in firm-specific characteristics and temporal trends, partially at the expense of other predictors. In auxiliary analysis we dropped the fixed effects and the exploration experience variables and found that other predictors, such as the firm's size, solvency and partnering experience significantly account for variance in exploration tendencies. Nevertheless, because our main concern was with controlling for unobserved heterogeneity rather than with uncovering the antecedents of exploration and exploitation, we retained the experience variables and fixed effects in the first-stage models. In accordance with Baum, Schaffer and Stillman (2003) we conducted Sargan difference tests for endogeneity (a robust version of the Hausman test) which confirmed that function exploration is endogenous in the market value model $\left(\chi^{2}=34.494, \mathrm{p}<\right.$ $0.0001)$ and that structure exploration is endogenous in the market value $\left(\chi^{2}=57.115, p<0.0001\right)$ and net profit models $\left(\chi^{2}=30.573, p<0.0001\right)$. Furthermore, we ran several tests to ensure that our instrumental variables in the first stage are relevant and significant. To offer conservative assessments we dropped the firm fixed effects when conducting these tests. Tests of joint significance of our endogenous regressors revealed that our instrumental variables are significant per the Anderson-Rubin Wald test and based on the Stock-Wright LMS statistic. Then, we used the weak identification test (Stock, Wright and Yogo 2002) that produced Cragg-Donald Wald F statistics which were larger than the Stock-Yogo critical value. These latter statistics are conservative since they account for size distortions to weak instruments and correct for the number of instruments (Bascle, 2008). Overall, these results indicate the strength of our instrumental variables and support our reliance on two-stage models. ${ }^{13}$

\footnotetext{
${ }^{13}$ In auxiliary analysis we ran single-stage models in which the original exploration variables were used with no correction for endogeneity. Consistent results were obtained with respect to the moderating effects of firm size on the relationships between balance within the function domain and the firm's market value and net profit as well as between balance within the structure domain and the firm's market value, in partial support of Hypothesis 3 . Additionally, the interactions of firm size with function exploration and structure exploration produced some significant effects in partial support of Hypothesis 4.
} 
TABLE 1

Descriptive Statistics and Pairwise Correlations for Sampled Firms during 1990-2001

\begin{tabular}{|c|c|c|c|c|c|c|c|c|c|c|c|c|c|c|c|}
\hline Variable & $\mathrm{N}$ & Mean & S.D. & 1. & 2. & 3. & 4. & 5. & 6. & 7. & 8. & 9. & 10. & 11. & 12. \\
\hline 1. Function Exploration ${ }_{t}$ & 2587 & 0.461 & 0.355 & & & & & & & & & & & & \\
\hline 2. Structure Exploration ${ }_{t}$ & 2406 & 0.892 & 0.188 & $-.099^{* * *}$ & & & & & & & & & & & \\
\hline 3. Firm Size ${ }_{t-1}$ & 2216 & 0.381 & 1.477 & .024 & $-.092^{* * *}$ & & & & & & & & & & \\
\hline 4. Firm Age 2001 & 2587 & 18.018 & 8.256 & -.008 & -.006 & $.067^{* *}$ & & & & & & & & & \\
\hline 5. Firm R\&D Intensity $t-1$ & 1965 & 0.347 & 1.099 & -.001 & .013 & $-.045^{*}$ & $-.141^{* * *}$ & & & & & & & & \\
\hline 6. Firm Solvency $t-1$ & 2204 & 4.592 & 4.508 & $.071^{* * *}$ & $-.110^{* * *}$ & $-.077^{* * *}$ & $-.049^{*}$ & .0044 & & & & & & & \\
\hline 7. Partnering Experience $t-1$ & 2587 & 22.238 & 55.373 & $.072^{* * *}$ & $-.218^{* * *}$ & $.533^{* * *}$ & .023 & -.028 & $.192^{* * *}$ & & & & & & \\
\hline 8. Function Explor. Experience ${ }_{\mathrm{t}-1}$ & 2244 & 0.469 & 0.278 & $.279^{* * *}$ & $-.118^{* * *}$ & .013 & -.013 & $.051^{*}$ & $.070^{* *}$ & $.088^{* * *}$ & & & & & \\
\hline 9. Structure Explor. Experience ${ }_{t-1}$ & 2070 & 0.925 & 0.095 & $-.144^{* * *}$ & $.251^{* * *}$ & $-.181^{* * *}$ & -.001 & -.020 & $-.170^{* * *}$ & $-.418^{* * *}$ & $-.220^{* * *}$ & & & & \\
\hline 10. Firm Market Value ${ }_{t+1}$ & 2306 & 2.125 & 17.646 & $.036^{\dagger}$ & $-.105^{* * *}$ & $.454^{* * *}$ & $.071^{* * *}$ & -.018 & $.106^{* * *}$ & $.721^{* * *}$ & $.054^{*}$ & $-.193^{* * *}$ & & & \\
\hline 11. Firm Net Profit $t_{t+1}$ & 2412 & 0.011 & 0.541 & $.014^{* * *}$ & $-.074^{* * *}$ & $.203^{* * *}$ & $.118^{* * *}$ & -.016 & $.053^{*}$ & $.503^{* * *}$ & .027 & $-.125^{* * *}$ & $.671^{* * *}$ & & \\
\hline 12. Firm Size ${ }_{t}$ & 2355 & 0.410 & 1.523 & .024 & $-.096^{* * *}$ & $.890^{* * *}$ & $.084^{* * *}$ & $-.049^{*}$ & $-.076^{* * *}$ & $.480^{* * *}$ & .011 & $-.166^{* * *}$ & $.561^{* * *}$ & -.011 & \\
\hline 13. Firm R\&D Intensity $t$ & 2121 & 0.359 & 1.103 & $.038^{\dagger}$ & $.042^{*}$ & $-.346^{* * *}$ & $-.126^{* * *}$ & $.564^{* * *}$ & $.044^{*}$ & -.033 & $.045^{*}$ & -.001 & -.019 & -.015 & $-.049^{*}$ \\
\hline 14. Firm Solvency $t$ & 2341 & 4.762 & 4.577 & $.077^{* * *}$ & $-.097^{* * *}$ & $-.097^{* * *}$ & $-.051^{*}$ & .003 & $.730^{* * *}$ & $.188^{* * *}$ & $.077^{* * *}$ & $-.160^{* * *}$ & $.100^{* * *}$ & $-.061^{* *}$ & $-.079^{* * *}$ \\
\hline 15. Size of Alliance Portfolio $t$ & 2564 & -0.959 & 3.038 & .003 & $.042^{*}$ & $-.346^{* * *}$ & $-.188^{* * *}$ & $.179^{* * *}$ & $.040^{\dagger}$ & $-.158^{* * *}$ & -.005 & $.113^{* * *}$ & $-.138^{* * *}$ & $-.042^{*}$ & $-.390^{* * *}$ \\
\hline 16. Alliance Age ${ }_{t}$ & 2587 & 1.767 & 0.529 & $.038^{\dagger}$ & $-.169^{* * *}$ & $.075^{* * *}$ & $.099^{* * *}$ & -.018 & $.109^{* * *}$ & $.220^{* * *}$ & -.002 & $-.167^{* * *}$ & .018 & .028 & $.067^{* *}$ \\
\hline 17. Partners per Alliance ${ }_{t}$ & 2587 & 2.158 & 0.603 & $.075^{* * *}$ & $-.097^{* * *}$ & $.131^{* * *}$ & $.069^{* * *}$ & -.025 & -.024 & $.129^{* * *}$ & $.078^{* * *}$ & $-.110^{* * *}$ & $.097^{* * *}$ & $.070^{* * *}$ & $.131^{* * *}$ \\
\hline 18. Agreements per Alliance ${ }_{t}$ & 2587 & 0.057 & 0.056 & $.269^{* * *}$ & $-.056^{* *}$ & -.008 & $.066^{* * *}$ & .018 & .025 & $-.037^{\dagger}$ & $.261^{* * *}$ & $-.048^{*}$ & -.007 & .005 & -.010 \\
\hline 19. \% Foreign Partners ${ }_{t}$ & 2587 & 0.176 & 0.196 & $-.053^{* *}$ & $-.046^{*}$ & -.010 & -.021 & .035 & .033 & $.045^{*}$ & .008 & $-.088^{* * *}$ & .011 & $.007^{* * *}$ & -.018 \\
\hline 20. \% Joint Ventures ${ }_{t}$ & 2587 & 0.033 & 0.105 & $-.045^{*}$ & .012 & $.128^{* * *}$ & $.121^{* * *}$ & -.018 & $-.145^{* * *}$ & .021 & -.009 & .025 & $.045^{*}$ & $.035^{\dagger}$ & $.117^{* * *}$ \\
\hline 21. \% Strategic Alliances ${ }_{t}$ & 2587 & 0.301 & 0.270 & $.155^{* * *}$ & $-.051^{*}$ & $.117^{* * *}$ & $.113^{* * *}$ & -.018 & $-.044^{*}$ & $.061^{* *}$ & $.130^{* * *}$ & $-.068^{* *}$ & $.088^{* * *}$ & $.066^{* *}$ & $.126^{* * *}$ \\
\hline 22. Acquisitions ${ }_{t}$ & 2587 & 0.817 & 2.018 & .018 & $-.093^{* * *}$ & $.471^{* * *}$ & $.106^{* * *}$ & $-.062^{* *}$ & 022 & $.470^{* * *}$ & .016 & $-.156^{* * *}$ & $.531^{* * *}$ & $.368^{* * *}$ & $.495^{* * *}$ \\
\hline
\end{tabular}

\begin{tabular}{|c|c|c|c|c|c|c|c|c|c|}
\hline Variable & 13. & 14. & 15. & 16. & 17. & 18. & 19. & 20. & 21. \\
\hline 14. Firm Solvency $t$ & .002 & & & & & & & & \\
\hline 15. Size of Alliance Portfolio $t$ & $.168^{* * *}$ & .014 & & & & & & & \\
\hline 16. Alliance Age ${ }_{t}$ & $-.041^{\dagger}$ & $.080^{* * *}$ & - & & & & & & \\
\hline 17. Partners per Alliance ${ }_{t}$ & -.022 & $-.357^{\dagger}$ & - & .016 & & & & & \\
\hline 18. Agreements per Alliance ${ }_{t}$ & $.040^{\dagger}$ & .022 & $-.044^{*}$ & -.010 & $.044^{*}$ & & & & \\
\hline 19. \% Foreign Partners ${ }_{t}$ & .039 & .029 & .008 & $.086^{* * *}$ & .014 & $.075^{* * *}$ & & & \\
\hline 20. \% Joint Ventures ${ }_{t}$ & -.014 & $-.138^{* * *}$ & - & -.030 & $.163^{* *}$ & $.047^{*}$ & $.118^{* *}$ & & \\
\hline 21. \% Strategic Alliances ${ }_{t}$ & -.010 & -.028 & - & $-.036^{\dagger}$ & $.166^{* *}$ & $.310^{* * *}$ & -.001 & -.016 & \\
\hline 22. Acquisitions ${ }_{t}$ & $-.055^{*}$ & .00 & - & $.070^{* * *}$ & $.076^{* *}$ & .008 & .004 & $.071^{* * *}$ & $.164^{* * *}$ \\
\hline
\end{tabular}

Significance levels: $\dagger p<.1, * p<.05, * * p<.01, * * * p<.001$ 
TABLE 2

Fixed Effects Panel AR(1) Second-Stage Models for Firm Market Value - Balance Within Domains

Dependent Variable: Market Value $_{t+1}$ Model Model Model Model Model Model Model

\begin{tabular}{lccccccl} 
& $1_{\mathrm{MV}}$ & $2_{\mathrm{MV}}$ & $3_{\mathrm{MV}}$ & $4_{\mathrm{MV}}$ & $5_{\mathrm{MV}}$ & $6_{\mathrm{MV}}$ & $7_{\mathrm{MV}}$ \\
\hline Intercept & 2.216 & -1.398 & $70.45^{* * *}$ & $66.35^{* * *}$ & -2.454 & $-71.03^{* * *}$ & $-52.86^{* * *}$ \\
& $(4.285)$ & $(5.588)$ & $(15.52)$ & $(16.19)$ & $(3.394)$ & $(10.14)$ & $(9.819)$
\end{tabular}

Firm Fixed Effects \& Year Dummies Included Included Included Included Included Included Included

Firm Size $_{\mathrm{t}}$

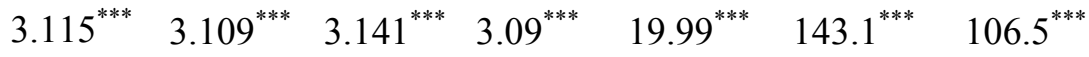

Firm R\&D Intensity ${ }_{t}$

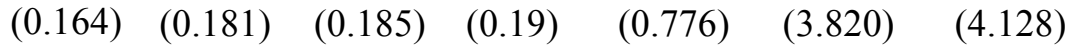

$\begin{array}{lllllll}-0.035 & -0.089 & -0.023 & -0.108 & 0.007 & -0.050 & -0.007\end{array}$

Firm Solvency ${ }_{t}$

$\begin{array}{lllllll}0.142) & (0.208) & (0.213) & (0.215) & (0.172) & (0.145) & (0.142)\end{array}$

$\begin{array}{lllllll}-0.015 & -0.003 & -0.010 & -0.002 & -0.030 & -0.034 & -0.040\end{array}$

Size of Alliance Portfolio $t$

$\begin{array}{lllllll}(0.042) & (0.050) & (0.053) & (0.053) & (0.035) & (0.034) & (0.031)\end{array}$

Size of Alliance Portolio,

Alliance Age $_{\mathrm{t}}$

$\begin{array}{lllllll}(0.180) & (0.227) & (0.244) & (0.243) & (0.153) & (0.152) & (0.139)\end{array}$

Partners per Alliance ${ }_{t}$

$\begin{array}{lllllll}-0.162 & 0.013 & 0.200 & 0.160 & -0.133 & 0.015 & -0.062 \\ (0.340) & (0.405) & (0.431) & (0.430) & (0.235) & (0.276) & (0.258)\end{array}$

$\begin{array}{lllllll}(0.340) & (0.405) & (0.431) & (0.430) & (0.235) & (0.276) & (0.258) \\ -0.512^{\dagger} & -0.813^{*} & -0.910^{*} & -0.884^{*} & -0.134 & 0.026 & 0.144\end{array}$

Agreements per Alliance $_{t}$

$(0.295) \quad(0.352)$

$-0.134$

$\begin{array}{lllllll}-3.259 & -3.378 & -6.526 & -4.721 & -3.183 & 0.156 & -1.930\end{array}$

$\%$ Foreign Partners ${ }_{t}$

$\begin{array}{lllllll}(3.664) & (4.953) & (5.586) & (5.617) & (3.271) & \text { (3.429) } & \text { (3.134) }\end{array}$

$\%$ Joint Venturest

$-0.701-1.232$

$-1.171-1.269$

$-0.147$

$-0.022$

0.147

\% Joint Ventures ${ }_{t}$

$\begin{array}{lllllll}0.955) & (1.262) & (1.380) & (1.376) & (0.837) & (0.851) & (0.774)\end{array}$

$\%$ Strategic Alliances ${ }_{t}$

$\begin{array}{lllllll}-3.029 & -5.470^{\dagger} & -5.816^{\dagger} & -5.719^{\dagger} & -2.200 & -3.832^{*} & -3.553^{*}\end{array}$

$\begin{array}{lllllll}(1.874) & (2.830) & (3.049) & (3.044) & (1.838) & (1.854) & (1.676)\end{array}$

Acquisitions

Acquisitions

$0.924 \quad 1.538$

$2.570^{*}$

$2.399^{*} 1.619^{*}$

$1.403^{\dagger}$

$1.451^{*}$

$\begin{array}{cc}(0.785) & (1.056) \\ 0.699^{* * *} & 0.800^{* * *}\end{array}$

$0.854^{* * *}$

$0.860^{* * *}$

$(0.690)$

$(0.729)$

$(0.657)$

$\begin{array}{lllllll}0.699^{* * *} & 0.800^{* * *} & 0.854^{* * *} & 0.860^{* * *} & 0.489^{* * *} & 0.135^{\dagger} & 0.087\end{array}$

Function Exploration $_{\mathrm{t}}$

(0.104)

Function Exploration ${ }_{t}^{2}$

$-12.10$

$(8.740)$

$(0.123)$

$(0.123) \quad(0.090)$

$(0.082)$

$(0.079)$

Structure Exploration $_{t}$

18.37
$(8.122)$

Structure Exploration ${ }_{\mathrm{t}}^{2}$

Firm Size $_{\mathrm{t}} \mathrm{x}$ Function Exploration $_{\mathrm{t}}$

Firm Size $_{\mathrm{t}} \mathrm{x}$ Function Exploration $_{\mathrm{t}}{ }^{2}$

$8.122)$

$-152.1^{* * *}-158.2^{* * *}(5.804)$

$-16.56 \quad 21.69^{* *}$

4.624

(11.29) (6.364)

$(6.603)$

Firm Size $_{\mathrm{t}} \mathrm{x}$ Structure Exploration $_{\mathrm{t}}$

$(35.53) \quad(35.51)$

$85.38^{* * *} 89.87^{* * *}$

$-10.70^{\dagger}$

(21.70) (21.69)

Firm Size $_{\mathrm{t}} \mathrm{x}$ Structure Exploration ${ }_{\mathrm{t}}{ }^{2}$

\begin{tabular}{llllllll} 
& & & & & & $(5.886)$ & $(6.874)$ \\
\hline AR(1) Parameter & 0.437 & 0.407 & 0.392 & 0.388 & 0.018 & 0.216 & 0.087 \\
N Firm-Years & 2041 & 1768 & 1674 & 1674 & 1768 & 1674 & 1674 \\
N Firms & 339 & 327 & 320 & 320 & 327 & 320 & 320 \\
VIF & 1.699 & 2.975 & 5.862 & 7.406 & 7.204 & 79.31 & 137.4 \\
-2Log Likelihood & 12427.3 & 10979.8 & 10458.6 & 10448.8 & 9782.0 & 8908.9 & 8673.7 \\
$\Delta$-2LL & & $7.4^{*}$ & $21.7^{* * *}$ & $31.5^{* * *}$ & $1205.2^{* * *}$ & $1571.4^{* * *}$ & $1806.6^{* * *}$ \\
\hline Exploration variables predicted from first-stage model. Significance levels: $\dagger p<.1, * p<.05, * *$ & $p<.01, * * *$ & $p<.001$
\end{tabular}


TABLE 3

Fixed Effects Panel AR(1) Second-Stage Models for Firm Net Profit - Balance Within Domains

Dependent Variable: Net Profit ${ }_{\mathrm{t}+1} \quad$ Model Model Model Model Model Model Model

\begin{tabular}{lccccccc} 
& $1_{\mathrm{NP}}$ & $2_{\mathrm{NP}}$ & $3_{\mathrm{NP}}$ & $4_{\mathrm{NP}}$ & $5_{\mathrm{NP}}$ & $6_{\mathrm{NP}}$ & $7_{\mathrm{NP}}$ \\
\hline Intercept & 0.176 & 0.064 & $2.508^{* *}$ & $2.415^{* *}$ & -0.098 & -1.485 & -0.703 \\
& $(0.292)$ & $(0.360)$ & $(0.886)$ & $(0.926)$ & $(0.283)$ & $(0.830)$ & $(0.798)$
\end{tabular}

Firm Fixed Effects \& Year Dummies Included Included Included Included Included Included Included

Firm Size ${ }_{t}$

Firm R\&D Intensity

Firm Solvency ${ }_{t}$

Size of Alliance Portfolio ${ }_{t}$

Alliance Age ${ }_{t}$

Partners per Alliance ${ }_{t}$

Agreements per Alliance $_{\mathrm{t}}$

$\%$ Foreign Partners ${ }_{t}$

$\%$ Joint Ventures ${ }_{\mathrm{t}}$

$\%$ Strategic Alliances ${ }_{t}$

Acquisitions

Function Exploration $_{\mathrm{t}}$

Function Exploration $_{\mathrm{t}}{ }^{2}$

Structure Exploration $_{\mathrm{t}}$

Structure Exploration ${ }_{\mathrm{t}}^{2}$

Firm Size $_{t} \mathrm{x}$ Function Exploration ${ }_{t}$

Firm Size $_{\mathrm{t}} \mathrm{x}$ Function Exploration ${ }_{\mathrm{t}}^{2}$

Firm Size $_{\mathrm{t}} \mathrm{x}$ Structure Exploration $_{\mathrm{t}}$

Firm Size $_{\mathrm{t}} \mathrm{x}$ Structure Exploration ${ }_{\mathrm{t}}^{2}$

\begin{tabular}{llllllll}
\hline AR(1) Parameter & 0.655 & 0.594 & 0.574 & 0.572 & 0.393 & 0.516 & 0.409 \\
N Firm-Years & 2072 & 1748 & 1651 & 1651 & 1748 & 1651 & 1651 \\
N Firms & 339 & 327 & 320 & 320 & 327 & 320 & 320 \\
VIF & 1.896 & 2.937 & 5.876 & 7.722 & 7.129 & 78.69 & 136.1 \\
-2Log Likelihood & 774.2 & 892.1 & 910.1 & 907.0 & 480.1 & 572.7 & 261.3 \\
$\Delta$-2LL & & 1.1 & $7.4^{*}$ & $10.5^{*}$ & $413.1^{* * *}$ & $344.8^{* * *}$ & $656.2^{* * *}$ \\
\hline
\end{tabular}

$-0.329^{* * *}-0.312^{* * *}-0.308^{* * *}-0.309^{* * *} 1.128^{* * *} 5.540^{* * *} 3.622^{* * *}$

$\begin{array}{lllllll}0.010) & (0.011) & (0.011) & (0.011) & (0.064) & (0.336) & (0.350)\end{array}$

$\begin{array}{lllllll}-0.002 & -0.002 & -0.001 & -0.002 & 0.0001 & -0.000 & -0.0001\end{array}$

$\begin{array}{lllllll}0.008) & (0.013) & (0.013) & (0.013) & (0.012) & (0.012) & (0.011)\end{array}$

$\begin{array}{lllllll}-0.001 & -0.001 & -0.002 & -0.001 & -0.003 & -0.003 & -0.003\end{array}$

$\begin{array}{lllllll}(0.002) & (0.003) & (0.003) & (0.003) & (0.003) & (0.003) & (0.003)\end{array}$

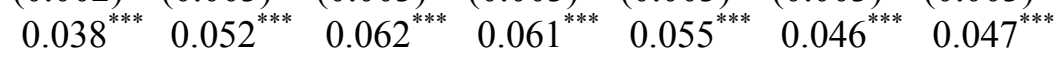

$\begin{array}{lllllll}(0.010) & (0.013) & (0.014) & (0.014) & (0.012) & (0.013) & (0.012)\end{array}$

$\begin{array}{lllllll}-0.014 & 0.0002 & 0.009 & 0.008 & 0.009 & 0.013 & 0.013\end{array}$

$\begin{array}{lllllll}(0.018) & (0.022) & (0.024) & (0.024) & (0.021) & (0.022) & (0.021)\end{array}$

$\begin{array}{lllllll}-0.027^{\dagger} & -0.054^{* *} & -0.062^{* *} & -0.061^{* *} & -0.055^{* *} & -0.050^{* *} & -0.053^{* *}\end{array}$

$\begin{array}{lllllll}0.016) & (0.020) & (0.021) & (0.021) & (0.018) & (0.019) & (0.018)\end{array}$

$\begin{array}{lllllll}-0.332 & -0.336 & -0.594^{\dagger} & -0.547^{\dagger} & -0.305 & -0.408 & -0.297\end{array}$

$\begin{array}{lllllll}(0.201) & (0.287) & (0.327) & (0.329) & (0.256) & (0.296) & (0.271)\end{array}$

$\begin{array}{lllllll}-0.017 & -0.013 & -0.008 & -0.012 & 0.045 & 0.021 & 0.071\end{array}$

$\begin{array}{lllllll}0.054) & (0.073) & (0.080) & (0.080) & (0.065) & (0.073) & (0.067)\end{array}$

$\begin{array}{lllllll}-0.006 & -0.028 & -0.040 & -0.039 & -0.126 & 0.005 & -0.130\end{array}$

$\begin{array}{lllllll}(0.104) & (0.162) & (0.179) & (0.178) & (0.143) & (0.160) & (0.145)\end{array}$

$\begin{array}{lllllll}-0.020 & 0.010 & 0.034 & 0.031 & 0.013 & 0.005 & 0.028\end{array}$

$\begin{array}{lllllll}(0.044) & (0.062) & (0.070) & (0.070) & (0.055) & (0.064) & (0.058)\end{array}$

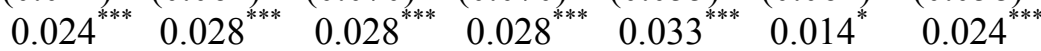

\begin{tabular}{ccccccc}
$(0.005)$ & $(0.006)$ & $(0.007)$ & $(0.007)$ & $(0.006)$ & $(0.006)$ & $(0.006)$ \\
\hline & -0.026 & & -0.674 & $1.552^{* * *}$ & 0.678
\end{tabular}

$\begin{array}{llll}(0.474) & (0.652) & (0.442) & (0.552)\end{array}$

0.233

(0.449)

$(0.591)(0.419)$

$-0.678$

$(0.504)$

$\begin{array}{llll}(1.988) & (1.989) & (1.882) & (1.763)\end{array}$

$3.154^{* *} \quad 3.265^{* *} \quad-2.215^{\dagger} \quad-0.686$

(1.216) (1.217)

$-6.433^{* * *}-5.367^{* * *}$

$(0.283) \quad(0.353)$

$6.624^{* * *} \quad 4.789^{* * *}$

(0.296) (0.380)

$-13.71^{* * *}-4.683^{* * *}$

$(0.840) \quad(0.958)$

$7.944^{* * *} 1.994^{* * *}$

$(0.523) \quad(0.591)$ 
TABLE 4

Fixed Effects Panel AR(1) Second-Stage Models for Firm Market Value - Balance Across Domains

\begin{tabular}{|c|c|c|c|c|c|c|c|c|}
\hline \multirow[t]{2}{*}{ Dependent Variable: } & \multicolumn{4}{|c|}{ Market Value $_{t+1}$} & \multicolumn{4}{|c|}{ Net Profit $_{t+1}$} \\
\hline & $\begin{array}{c}\text { Model } \\
1_{\mathrm{MV}}\end{array}$ & $\begin{array}{l}\text { Model } \\
8_{\mathrm{MV}}\end{array}$ & $\begin{array}{c}\text { Model } \\
9_{\mathrm{MV}}\end{array}$ & $\begin{array}{l}\text { Model } \\
10_{\mathrm{MV}}\end{array}$ & $\begin{array}{c}\text { Model } \\
1_{\mathrm{NP}}\end{array}$ & $\begin{array}{c}\text { Model } \\
8_{\mathrm{NP}}\end{array}$ & $\begin{array}{c}\text { Model } \\
9_{\mathrm{NP}}\end{array}$ & $\begin{array}{c}\text { Model } \\
10_{\mathrm{NP}}\end{array}$ \\
\hline Intercept & $\begin{array}{c}2.216 \\
(4.285)\end{array}$ & $\begin{array}{c}6.942 \\
(8.309)\end{array}$ & $\begin{array}{l}-32.05^{*} \\
(12.77)\end{array}$ & $\begin{array}{c}16.67^{*} \\
(7.159)\end{array}$ & $\begin{array}{c}0.176 \\
(0.292)\end{array}$ & $\begin{array}{c}0.258 \\
(0.430)\end{array}$ & $\begin{array}{l}-1.081 \\
(0.733)\end{array}$ & $\begin{array}{c}0.043 \\
(0.606)\end{array}$ \\
\hline $\begin{array}{l}\text { Firm Fixed Effects \& Year Dummies } \\
\text { Firm Size }_{t}\end{array}$ & $\begin{array}{l}\text { Included } \\
3.115^{* * *} \\
(0.164)\end{array}$ & $\begin{array}{l}\text { Included } \\
3.141^{* * *} \\
(0.186)\end{array}$ & $\begin{array}{l}\text { Included } \\
3.072^{* * *} \\
(0.186)\end{array}$ & $\begin{array}{l}\text { Included } \\
-71.89^{* * *} \\
(3.132)\end{array}$ & $\begin{array}{l}\text { Included } \\
-0.329^{* * *} \\
(0.010)\end{array}$ & $\begin{array}{l}\text { Included } \\
-0.308^{* * *} \\
(0.010)\end{array}$ & $\begin{array}{l}\text { Included } \\
-0.309^{* * *} \\
(0.011)\end{array}$ & $\begin{array}{l}\text { Included } \\
-2.617^{* * *} \\
(0.277)\end{array}$ \\
\hline Firm R\&D Intensity ${ }_{t}$ & $\begin{array}{l}-0.035 \\
(0.142)\end{array}$ & $\begin{array}{l}-0.089 \\
(0.215)\end{array}$ & $\begin{array}{l}-0.084 \\
(0.215)\end{array}$ & $\begin{array}{l}-0.035 \\
(0.135)\end{array}$ & $\begin{array}{l}-0.002 \\
(0.008)\end{array}$ & $\begin{array}{l}-0.001 \\
(0.013)\end{array}$ & $\begin{array}{l}-0.002 \\
(0.013)\end{array}$ & $\begin{array}{l}-0.002 \\
(0.011)\end{array}$ \\
\hline Firm Solvency ${ }_{t}$ & $\begin{array}{l}-0.015 \\
(0.042)\end{array}$ & $\begin{array}{l}-0.002 \\
(0.053)\end{array}$ & $\begin{array}{l}-0.005 \\
(0.053)\end{array}$ & $\begin{array}{l}-0.066^{*} \\
(0.030)\end{array}$ & $\begin{array}{l}-0.001 \\
(0.002)\end{array}$ & $\begin{array}{l}-0.001 \\
(0.003)\end{array}$ & $\begin{array}{l}-0.001 \\
(0.003)\end{array}$ & $\begin{array}{l}-0.004 \\
(0.003)\end{array}$ \\
\hline Size of Alliance Portfolio $t$ & $\begin{array}{l}0.699^{* * *} \\
(0.180)\end{array}$ & $\begin{array}{l}1.014^{* * *} \\
(0.245)\end{array}$ & $\begin{array}{l}0.985^{* * *} \\
(0.244)\end{array}$ & $\begin{array}{c}0.134 \\
(0.135)\end{array}$ & $\begin{array}{l}0.038^{* * *} \\
(0.010)\end{array}$ & $\begin{array}{l}0.060^{* * *} \\
(0.014)\end{array}$ & $\begin{array}{l}0.059^{* * *} \\
(0.014)\end{array}$ & $\begin{array}{l}0.040^{* * *} \\
(0.012)\end{array}$ \\
\hline Alliance Age ${ }_{t}$ & $\begin{array}{l}-0.162 \\
(0.340)\end{array}$ & $\begin{array}{c}0.159 \\
(0.433)\end{array}$ & $\begin{array}{c}0.099 \\
(0.431)\end{array}$ & $\begin{array}{l}-0.009 \\
(0.249)\end{array}$ & $\begin{array}{l}-0.014 \\
(0.018)\end{array}$ & $\begin{array}{c}0.008 \\
(0.024)\end{array}$ & $\begin{array}{c}0.006 \\
(0.024)\end{array}$ & $\begin{array}{c}0.015 \\
(0.020)\end{array}$ \\
\hline Partners per Alliance $_{t}$ & $\begin{array}{l}-0.512^{\dagger} \\
(0.295)\end{array}$ & $\begin{array}{l}-0.934^{*} \\
(0.370)\end{array}$ & $\begin{array}{l}-0.919^{*} \\
(0.368)\end{array}$ & $\begin{array}{l}0.245 \\
(0.204)\end{array}$ & $\begin{array}{l}-0.027^{\dagger} \\
(0.016)\end{array}$ & $\begin{array}{l}-0.063^{* *} \\
(0.021)\end{array}$ & $\begin{array}{l}-0.062^{* *} \\
(0.021)\end{array}$ & $\begin{array}{l}-0.054^{* *} \\
(0.018)\end{array}$ \\
\hline Agreements per Alliance $_{t}$ & $\begin{array}{l}-3.259 \\
(3.664)\end{array}$ & $\begin{array}{l}-4.443 \\
(5.651)\end{array}$ & $\begin{array}{l}-3.927 \\
(5.623)\end{array}$ & $\begin{array}{l}-4.864 \\
(3.053)\end{array}$ & $\begin{array}{l}-0.332 \\
(0.201)\end{array}$ & $\begin{array}{l}-0.521 \\
(0.329)\end{array}$ & $\begin{array}{l}-0.507 \\
(0.328)\end{array}$ & $\begin{array}{l}-0.395 \\
(0.268)\end{array}$ \\
\hline$\%$ Foreign Partners ${ }_{t}$ & $\begin{array}{l}-0.701 \\
(0.955)\end{array}$ & $\begin{array}{l}-1.211 \\
(1.385)\end{array}$ & $\begin{array}{l}-1.228 \\
(1.378)\end{array}$ & $\begin{array}{l}-0.448 \\
(0.753)\end{array}$ & $\begin{array}{l}-0.017 \\
(0.054)\end{array}$ & $\begin{array}{l}-0.006 \\
(0.081)\end{array}$ & $\begin{array}{l}-0.006 \\
(0.080)\end{array}$ & $\begin{array}{c}0.042 \\
(0.066)\end{array}$ \\
\hline$\%$ Joint Ventures $_{t}$ & $\begin{array}{l}-3.029 \\
(1.874)\end{array}$ & $\begin{array}{l}-6.695^{*} \\
(3.061)\end{array}$ & $\begin{array}{l}-6.290^{*} \\
(3.044)\end{array}$ & $\begin{array}{l}-5.309^{* *} \\
(1.631)\end{array}$ & $\begin{array}{l}-0.006 \\
(0.104)\end{array}$ & $\begin{array}{l}-0.066 \\
(0.178)\end{array}$ & $\begin{array}{l}-0.045 \\
(0.178)\end{array}$ & $\begin{array}{l}-0.176 \\
(0.143)\end{array}$ \\
\hline$\%$ Strategic Alliances $_{t}$ & $\begin{array}{l}0.924 \\
(0.785)\end{array}$ & $\begin{array}{l}2.099^{*} \\
(1.197)\end{array}$ & $\begin{array}{l}2.402^{*} \\
(1.193)\end{array}$ & $\begin{array}{l}1.735^{* *} \\
(0.638)\end{array}$ & $\begin{array}{l}-0.020 \\
(0.044)\end{array}$ & $\begin{array}{l}0.019 \\
(0.070)\end{array}$ & $\begin{array}{l}0.030 \\
(0.070)\end{array}$ & $\begin{array}{l}0.030 \\
(0.057)\end{array}$ \\
\hline Acquisitions & $\begin{array}{l}0.699^{* * *} \\
(0.104)\end{array}$ & $\begin{array}{c}0.863^{* * *} \\
(0.123)\end{array}$ & $\begin{array}{l}0.869^{* * *} \\
(0.123)\end{array}$ & $\begin{array}{c}0.080 \\
(0.075)\end{array}$ & $\begin{array}{l}0.024^{* * *} \\
(0.005)\end{array}$ & $\begin{array}{c}0.029^{* * *} \\
(0.007)\end{array}$ & $\begin{array}{c}0.029^{* * *} \\
(0.007)\end{array}$ & $\begin{array}{l}0.022^{* * *} \\
(0.006)\end{array}$ \\
\hline Function Exploration $_{t}$ & & $\begin{array}{c}8.635^{\dagger} \\
(4.819)\end{array}$ & $\begin{array}{l}84.47^{* * *} \\
(19.49)\end{array}$ & $\begin{array}{l}-39.58^{* * *} \\
(11.20)\end{array}$ & & $\begin{array}{c}0.233 \\
(0.277)\end{array}$ & $\begin{array}{c}2.862^{* *} \\
(1.091)\end{array}$ & $\begin{array}{l}-0.533 \\
(0.932)\end{array}$ \\
\hline Structure Exploration $_{\mathrm{t}}$ & & $\begin{array}{l}-12.96^{*} \\
(5.553)\end{array}$ & $\begin{array}{c}30.83^{*} \\
(19.49)\end{array}$ & $\begin{array}{l}-16.40^{*} \\
(7.045)\end{array}$ & & $\begin{array}{l}-0.233 \\
(0.311)\end{array}$ & $\begin{array}{c}1.276^{\dagger} \\
(0.681)\end{array}$ & $\begin{array}{c}0.068 \\
(0.582)\end{array}$ \\
\hline $\begin{array}{l}\text { Function Exploration }_{t} \times \\
\text { Structure Exploration }_{t} \\
\text { Firm Size }_{\mathrm{t}} \text { X Function Exploration }\end{array}$ & & & $\begin{array}{l}-84.39^{* * *} \\
(21.03)\end{array}$ & $\begin{array}{l}42.06^{* * *} \\
(12.10)^{* * *} \\
170.07^{* *} \\
(4.591)\end{array}$ & & & $\begin{array}{l}-2.928^{*} \\
(1.175)\end{array}$ & $\begin{array}{l}0.788 \\
(1.006) \\
6.314^{* * *} \\
(0.406)\end{array}$ \\
\hline Firm Size $_{t}$ x Structure Exploration ${ }_{t}$ & & & & $\begin{array}{l}78.66^{* * *} \\
(3.283)\end{array}$ & & & & $\begin{array}{l}3.074^{* * *} \\
(0.291)\end{array}$ \\
\hline $\begin{array}{l}\text { Firm Size }_{\mathrm{t}} \text { X Function Exploration } \\
\mathrm{t} \\
\text { Structure Exploration } \\
\text { t }_{\mathrm{t}}\end{array}$ & & & & $\begin{array}{l}-188.7^{* * *} \\
(4.929)\end{array}$ & & & & $\begin{array}{l}-8.277^{* * *} \\
(0.437)\end{array}$ \\
\hline AR(1) Parameter & 0.437 & 0.395 & 0.389 & 0.134 & 0.655 & 0.575 & 0.571 & 0.404 \\
\hline N Firm-Years & 2041 & 1674 & 1674 & 1674 & 2072 & 1651 & 1651 & 1651 \\
\hline N Firms & 339 & 320 & 320 & 320 & 339 & 320 & 320 & 320 \\
\hline VIF & 1.699 & 2.317 & 6.269 & 34.78 & 1.896 & 2.356 & 6.152 & 34.56 \\
\hline $\begin{array}{l}\text {-2Log Likelihood } \\
\Delta \text {-2LL }\end{array}$ & 12427.3 & $\begin{array}{l}10470.8 \\
9.5^{* *}\end{array}$ & $\begin{array}{l}10454.8 \\
25.5^{* * *}\end{array}$ & $\begin{array}{l}8545.7 \\
1934.6^{* * *}\end{array}$ & 774.2 & $\begin{array}{l}916.2 \\
1.3\end{array}$ & $\begin{array}{l}910.0 \\
24.1^{\dagger}\end{array}$ & $\begin{array}{l}229.3 \\
688.2^{* * *}\end{array}$ \\
\hline
\end{tabular}

Exploration variables predicted from first-stage model. Significance levels: $\uparrow p<.1, * p<.05, * * p<.01, * * * p<.001$ 
TABLE 5

Summary of Results

\begin{tabular}{l|l|l}
\hline Dependent Variable: & \multicolumn{1}{|c}{ Market Value } & \multicolumn{1}{c}{ Net Profit } \\
\hline $\begin{array}{l}\text { H1 Balance within } \\
\text { (a) Function domain }(\cup) \\
(\text { a) Structure domain }(\cup)\end{array}$ & $\begin{array}{l}\text { Partial support (linear term n.s.) } \\
\text { Supported }\end{array}$ & $\begin{array}{l}\text { n.s. } \\
\text { Supported }\end{array}$ \\
\hline $\begin{array}{l}\text { H2 Balance across domains } \\
\text { (negative interaction) }\end{array}$ & Supported & Supported \\
\hline $\begin{array}{l}\text { H3 Size moderation of balance within } \\
\text { (a) Function domain }(\rightarrow \cup) \\
(\text { a) Structure domain }(\rightarrow \cup)\end{array}$ & $\begin{array}{l}\text { Supported } \\
\text { Supported }\end{array}$ & $\begin{array}{l}\text { Supported } \\
\text { Supported }\end{array}$ \\
\hline $\begin{array}{l}\text { H4 Balance across domains } \\
\text { (negative three-way interaction) }\end{array}$ & Supported & $\begin{array}{l}\text { Partial support } \\
\text { (unmoderated terms n.s.) }\end{array}$ \\
\hline
\end{tabular}


TABLE 6

Fixed Effects Panel AR(1) First-Stage Tobit Models for Function/Structure Exploration

\begin{tabular}{|c|c|c|}
\hline & $\begin{array}{c}\text { Function } \\
\text { Exploration }_{\mathrm{t}}\end{array}$ & $\begin{array}{c}\text { Structure } \\
\text { Exploration }_{\mathrm{t}}\end{array}$ \\
\hline Intercept & $\begin{array}{l}1.073^{* * *} \\
(0.227)\end{array}$ & $\begin{array}{l}1.524^{* * *} \\
(0.185)\end{array}$ \\
\hline Firm Fixed Effects & Included & Included \\
\hline Year 1990 & $\begin{array}{l}0.087 \\
(0.084)\end{array}$ & $\begin{array}{l}0.316^{* * *} \\
(0.060)\end{array}$ \\
\hline Year 1991 & $\begin{array}{l}0.081 \\
(0.057)\end{array}$ & $\begin{array}{l}0.216^{* * *} \\
(0.040)\end{array}$ \\
\hline Year 1992 & $\begin{array}{c}0.095^{\dagger} \\
(0.050)\end{array}$ & $\begin{array}{l}0.101^{* *} \\
(0.033)\end{array}$ \\
\hline Year 1993 & $\begin{array}{c}0.015 \\
(0.043)\end{array}$ & $\begin{array}{c}0.049^{\dagger} \\
(0.029)\end{array}$ \\
\hline Year 1994 & $\begin{array}{c}0.062 \\
(0.039)\end{array}$ & $\begin{array}{l}0.093^{* * *} \\
(0.025)\end{array}$ \\
\hline Year 1995 & $\begin{array}{c}0.085^{*} \\
(0.034)\end{array}$ & $\begin{array}{c}0.026 \\
(0.022)\end{array}$ \\
\hline Year 1996 & $\begin{array}{l}0.124^{* * *} \\
(0.029)\end{array}$ & $\begin{array}{l}0.056^{* *} \\
(0.019)\end{array}$ \\
\hline Year 1997 & $\begin{array}{l}0.105^{* * *} \\
(0.028)\end{array}$ & $\begin{array}{c}0.056^{* *} \\
(0.015)\end{array}$ \\
\hline Year 1998 & $\begin{array}{c}0.045^{\dagger} \\
(0.024)\end{array}$ & $\begin{array}{l}0.008 \\
(0.015)\end{array}$ \\
\hline Year 1999 & $\begin{array}{c}0.039^{\dagger} \\
(0.024)\end{array}$ & $\begin{array}{l}-0.000 \\
(0.014)\end{array}$ \\
\hline Year 2000 & $\begin{array}{c}0.037 \\
(0.023)\end{array}$ & $\begin{array}{l}-0.001 \\
(0.015)\end{array}$ \\
\hline Year 2001 & & \\
\hline Firm Size $_{t-1}$ & $\begin{array}{l}-0.001 \\
(0.008)\end{array}$ & $\begin{array}{l}0.002 \\
(0.005)\end{array}$ \\
\hline Firm Age $_{2001}$ & $\begin{array}{l}-0.005 \\
(0.025)\end{array}$ & $\begin{array}{l}-0.004 \\
(0.019)\end{array}$ \\
\hline Firm R\&D Intensity $\mathrm{t}-1$ & $\begin{array}{l}-0.012 \\
(0.008)\end{array}$ & $\begin{array}{l}0.004 \\
(0.005)\end{array}$ \\
\hline Firm Solvency ${ }_{t-1}$ & $\begin{array}{l}-0.001 \\
(0.002)\end{array}$ & $\begin{array}{l}-0.000 \\
(0.001)\end{array}$ \\
\hline Partnering Experience $_{t-1}$ & $\begin{array}{l}0.000 \\
(0.000)\end{array}$ & $\begin{array}{l}-0.001^{*} \\
(0.000)\end{array}$ \\
\hline Function Explor. Experience $_{t-1}$ & $\begin{array}{l}-0.259^{* * *} \\
(0.045)\end{array}$ & \\
\hline Structure Explor. Experience ${ }_{t-1}$ & & $\begin{array}{l}-0.601^{* * *} \\
(0.085)\end{array}$ \\
\hline AR(1) Parameter & -0.069 & -0.124 \\
\hline N Firm-Years & 1820 & 1722 \\
\hline N Firms & 330 & 322 \\
\hline -2Log Likelihood & 271.9 & 1431.5 \\
\hline
\end{tabular}

Significance levels: $\dagger p<.1, * p<.05, * * p<.01, * * * p<.001$ 
FIGURE 1

Impact of Balance Within the Function and Structure Domains on Market Value and Net Profit
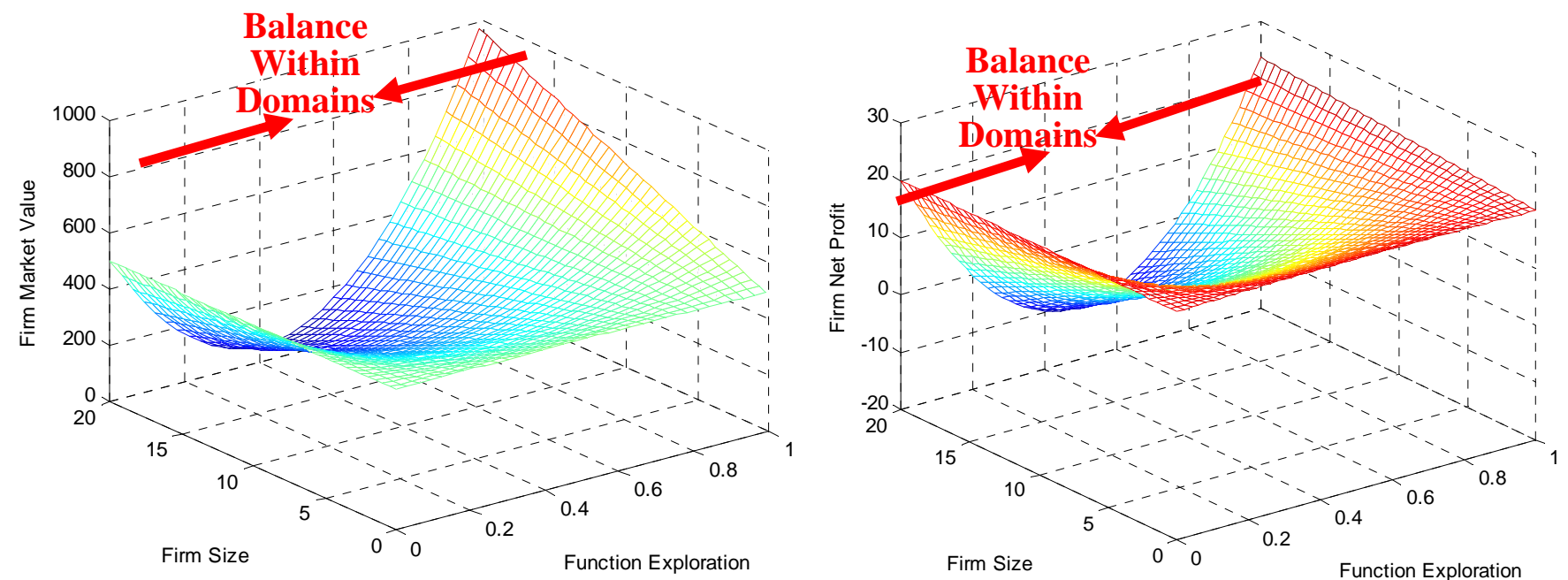

Model 5: Balance within the function domain
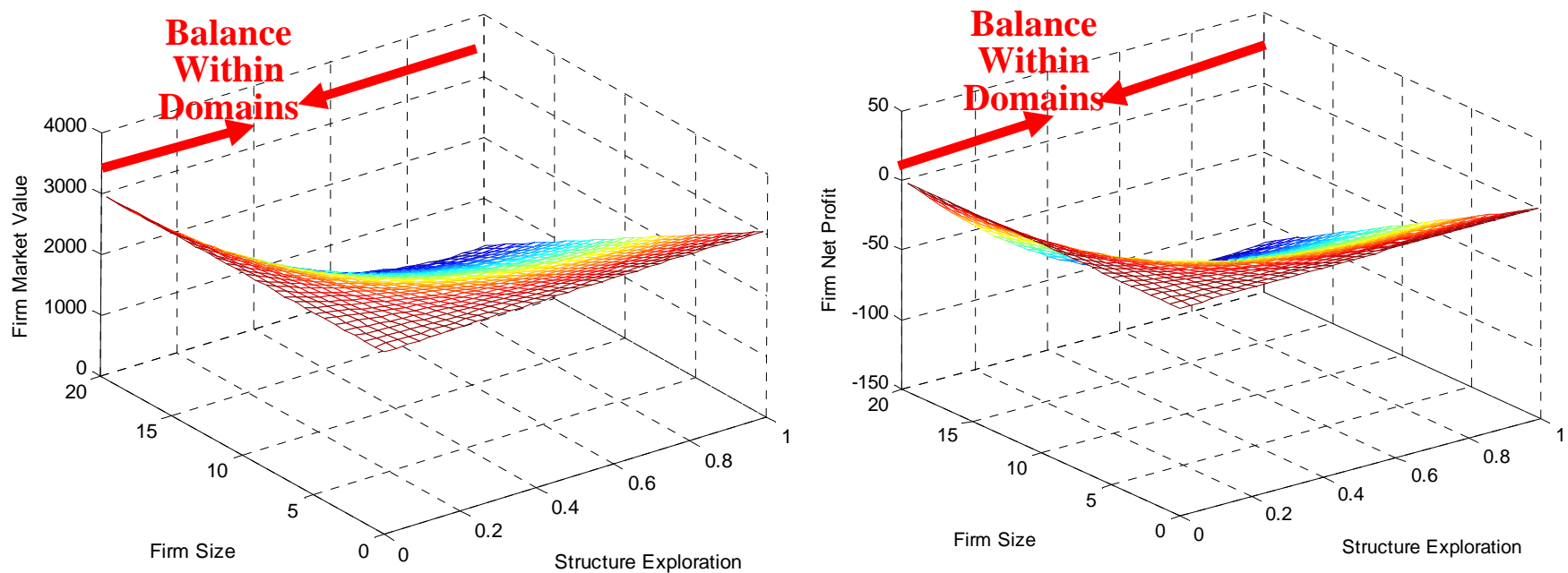

Model 6: Balance within the structure domain 
FIGURE 2

Impact of Balance Across the Function and Structure Domains on Market Value and Net Profit
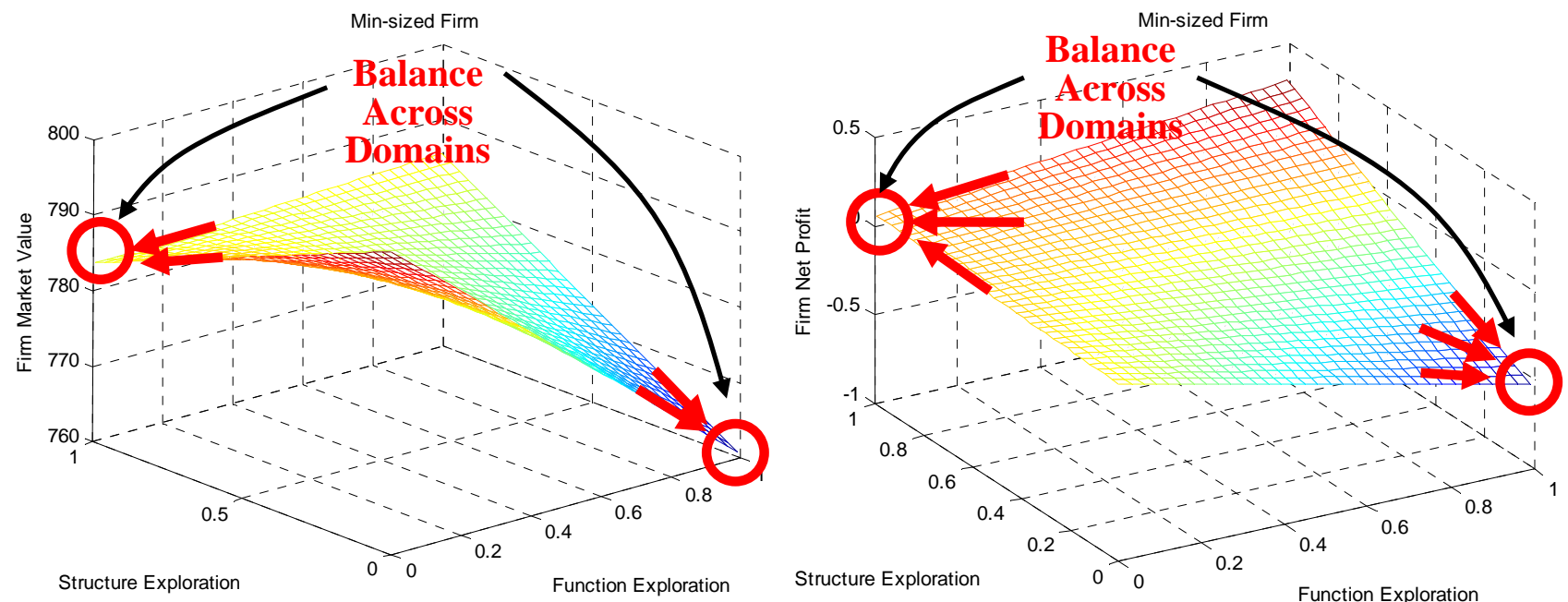

Model 10: Balance across domains (min-sized firm)
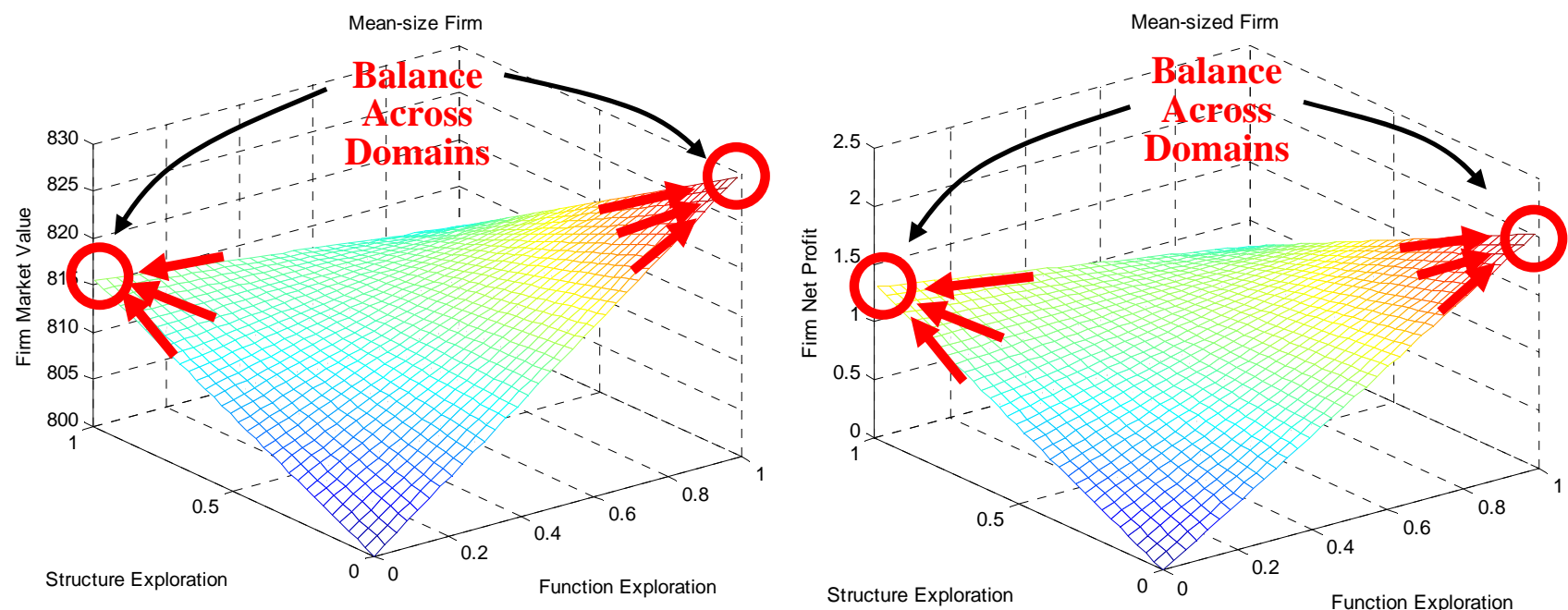

Model 10: Balance across domains (mean-sized firm)
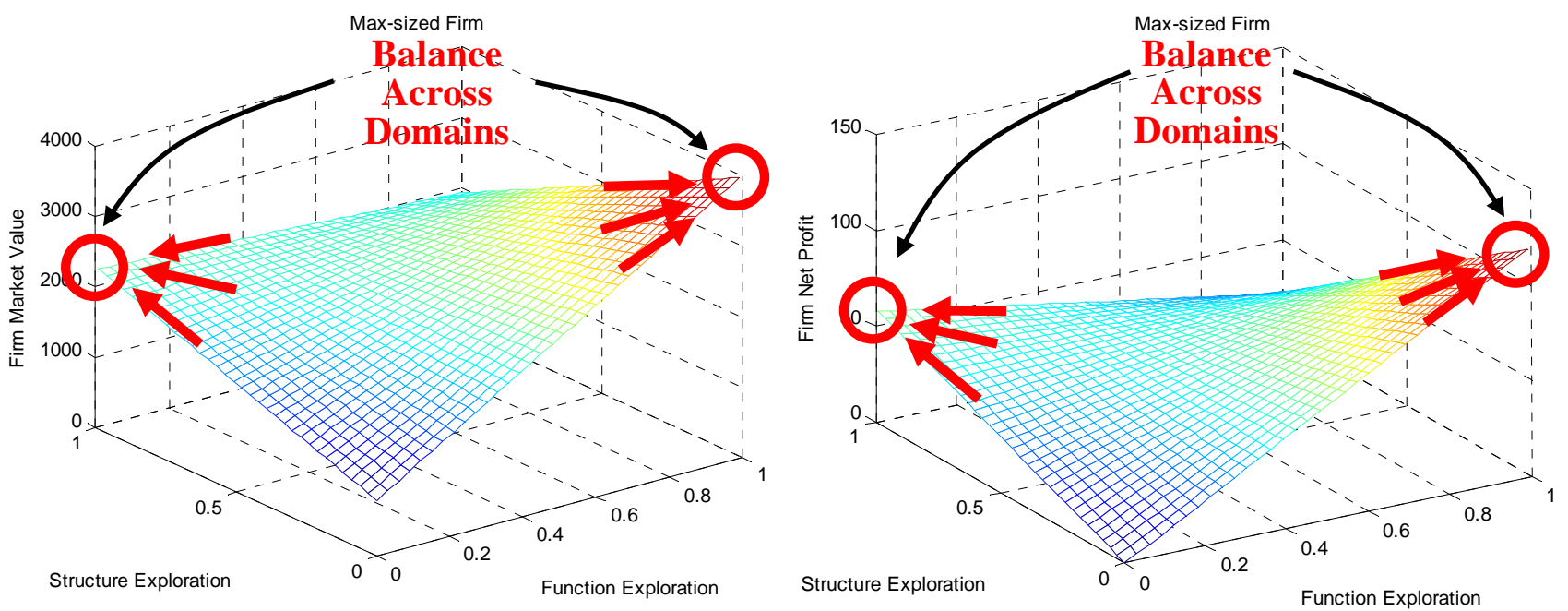

Model 10: Balance across domains (max-sized firm) 


\section{References}

Abernathy, W.J. 1978. The productivity dilemma. Johns Hopkins University Press, Baltimore.

Ahuja, G. 2000. Collaboration networks, structural holes, and innovation: A longitudinal study. Admin. Sci. Quart. 45(3) 425-455.

Baltagi, B.H., P.X. Wu. 1999. Unequally spaced panel data regressions with AR(1) disturbances. Econometric Theory 15 814-823.

Barnett, W.P., H.R. Greve, D.Y. Park. 1994. An evolutionary model of organizational performance. Strategic Management J. 15(Winter Special issue) 11-28.

Bascle, G. 2008. Controlling for endogeneity with instrumental variables in strategic management research. Strategic Organ. 6(3) 285-327.

Baum, J.A.C., T. Calabrese, B.S. Silverman. 2000. Don't go it alone: Alliance network composition and startups' performance in Canadian biotechnology. Strategic Management J. 21 267-294.

Baum, J.A.C., T. Rowley, A.V. Shipilov, Y.-T. Chuang. 2005. Dancing with strangers: Aspiration performance and the search for underwriting syndicate partners. Admin. Sci. Quart. 50 536-575.

Beckman, C.M., P.R. Haunschild, D.J. Phillips. 2004. Friends or strangers? Firm-specific uncertainty, market uncertainty, and network partner selection. Organ. Sci. 15(3) 259-275.

Benner, M.J., M.L. Tushman. 2003. Exploitation, exploration, and process management: The productivity dilemma revisited. Acad. of Management Rev. 28(2) 238-256.

Blundell, R., R. Griffith, J. Van Reenen. 1995. Dynamic count data models of technological innovation. The Econom. J. 105(429) 333-344.

Bourgeois, L.J. 1981. On the measurement of organizational slack. Acad. of Management Rev. 6(1) 29-39.

Brown, S.L., K.M. Eisenhardt. 1997. The art of continuous change: Linking complexity theory and time-paced evolution in relentlessly shifting organizations. Admin. Sci. Quart. 42 1-34.

Brush, T.H., P. Bromiley, M. Hendrickx. 2000. The free cash flow hypothesis for sales growth and firm performance. Strategic Management J. 21(4) 455-472.

Burt, R.S. 2000. The network structure of social capital. Res. in Organ. Behavior 22 345-423.

Child, J. 1972. Organization structure, environment, and perfomrance: The role of strategic choice. Sociology 6(1) 1-22.

Christensen, C.M. 1998. The innovator's dilemma: When new technologies cause great firms to fail. Harvard Business School Press, Boston.

Chung, S., H. Singh, K. Lee. 2000. Complementarity, status similarity and social capital as drivers of alliance formation. Strategic Management J. 21(1) 1-22.

Contractor, F., S. Kundu, C.-C. Hsu. 2003. A three-stage theory of international expansion: The link between multinationality and performance in the service sector. J. of Internat. Bus. Stud. 34 5-18.

Cyert, R.M., J.G. March. 1963. A Behavioral Theory of the Firm 2nd ed. Prentice-Hall, Englewood Cliffs, NJ.

Duncan, R.B. 1976. The ambidextrous organization: designing dual structures for innovation North Holland, New York.

Dyer, J.H. 2000. Collaborative Advantage: Winning through extended enterprise supplier networks. Oxford University Press, New York.

Gibson, C.B., J. Birkinshaw. 2004. The antecedens, consequences, and mediating role of organizational ambidexterity. Academy of Management J. 47(2) 209-226.

Grant, R.M., C. Baden-Fuller. 2004. A knowledge accessing theory of strategic alliances. J. of Management Stud. 41(1) 61-84.

Gulati, R. 1995a. Does familiarity breed trust? The implications of repeated ties for contractual choices. Academy of Management J. 35(4) 85-112.

Gulati, R. 1995b. Social structure and alliance formation patterns: A longitudinal analysis. Admin. Sci. Quart. 40(4) 619-652.

Gulati, R. 1998. Alliances and networks. Strategic Management J. 19(4) 293-317.

Gulati, R. 1999. Network location and learning: The influence of network resources and firm capabilities on alliance formation. Strategic Management J. 20(5) 397-420.

Gulati, R., M. Gargiulo. 1999. Where do interorganizational networks come from? Amer. J. of Sociology 104(5) 1439-1493. 
Gulati, R., M.C. Higgins. 2003. Which ties matter when? The contingent effects of interorganizational partnerships on IPO success. Strategic Management J. 24(2) 127-144.

Gulati, R., H. Singh. 1998. The architecture of cooperation: Managing coordination costs and appropriation concerns in strategic alliances. Admin. Sci. Quart. 43(4) 781-814.

Gupta, A.K., K.G. Smith, C.E. Shalley. 2006. The interplay between exploration and exploitation. Acad. of Management J. 49 693-706.

Hagedoorn, J. 1993. Understanding the rationale of strategic technology partnering. Strategic Management J. 14(5) 371-385.

Hamilton, B.H., J.A. Nickerson. 2003. Correction for endogeneity in strategic management research. Strategic Organ. 1(1) 51-78.

Hannan, M.T., J.H. Freeman. 1977. The population ecology of organizations. Amer. J. of Sociology 82(5) 929964.

Hannan, M.T., J.H. Freeman. 1984. Structural inertia and organizational change. Amer. Sociological Rev. 49(2) 149-164.

He, Z.-L., P.-K. Wong. 2004. Exploration vs. exploitation: An empirical test of the ambidexterity hypothesis. Organ. Sci. 15(4) 481-494.

Hoang, H., F. T. Rothaermel. 2005. The effect of general and partner-specific alliance experience on joint R\&D project performance. Acad. of Management J. 48(2) 332-345.

Hoffmann, W.H. 2007. Strategies for managing a portfolio of alliances. Strategic Management J. 28(8) 827-856.

Jansen, J.J., F.A.J. Van Den Bosch, H.W. Volberda. 2006. Exploratory innovation, exploitative innovation, and performance: Effects of organizational antecedents and environmental moderators. Management Sci. 52(11) 1661-1674.

Jensen, R., G. Szulanski. 2004. Stickiness and the adaptation of organizational practices in cross-border knowledge transfers. J. of Internat. Bus. Stud. 35(6) 508-523.

Kale, P., J.H. Dyer, H. Singh. 2002. Alliance capability, stock market response, and long-term alliance success: The role of the alliance function. Strategic Management J. 23(8) 747-767.

Kale, P., H. Singh, H. Perlmutter. 2000. Learning and protection of proprietary assets in strategic alliances: Building relational capital. Strategic Management J. 21(3) 217-237.

Kalmbach, C.J., C. Roussel. 1999. Dispelling the Myths of Alliances. Outlook October(Special Edition) 5-32.

Kelly, D., T.L. Amburgey. 1991. Organizational inertia and momentum: A dynamic model of strategic change. Acad. of Management J. 34(3) 591-612.

Kleinbaum, D.G., L.K. Lawrence, K.E. Muller, A. Nizam. 1998. Applied regression analysis and other multivariable methods, 3rd ed. Brooks/Cole Publishing Company, Pacific Grove, CA.

Koza, M.P., A.Y. Lewin. 1998. The co-evolution of strategic alliances. Organ. Sci. 9(3) 255-264.

Koza, M.P., A.Y. Lewin. 2000. Managing partnerships and strategic alliances: Raising the odds of success. Eur. Management J. 18(2) 146-151.

Lavie, D. 2006. The competitive advantage of interconnected firms: An extension of the resource-based view. Acad. of Management Rev. 31(3) 638-658.

Lavie, D. 2007. Alliance portfolios and firm performance: A study of value creation and appropriation in the U.S. software industry. Strategic Management J. 28(12) 1187-1212.

Lavie, D., S. Miller. 2008. Alliance portfolio internationalization and firm performance. Organ. Sci. .

Lavie, D., L. Rosenkopf. 2006. Balancing exploration and exploitation in alliance formation. Acad. of Management J. 49(6) 797-818.

Lee, C., K. Lee, J.M. Pennings. 2001. Internal capabilities, external networks, and performance: a study on technology-based ventures. Strategic Management J. 22 615-640.

Levinthal, D.A., J.G. March. 1981. A model of adaptive organizational search. J. of Econom. Behavior \& Organ. 2(4) 307-333.

Levinthal, D.A., J.G. March. 1993. The myopia of learning. Strategic Management J. 14(special issue) 95-112.

Li, S.X., T.J. Rowley. 2002. Inertia and evaluation mechanisms in interorganizational partner selection: Syndicate formation among U.S. investment banks. Acad. of Management J. 45(6) 1104-1119.

Lin, Z., Yang, H., \& Demirkan, I. 2007. The performance consequences of ambidexterity in strategic alliance formations: Empirical investigation and computational theorizing. Management Sci., 53(10): 1645-1658. 
Lubatkin, M., R. Shrieves. 1986. Toward reconciliation of market performance measures to strategic management research. Acad. of Management Executive 11(497-512).

Maddala, G.S. 2001. Introduction to Econometrics, 3rd ed. John Wiley \& Sons, New York, NY.

March, J.G. 1976. The technology of foolishness. J.G. March, J.P. Olsen, eds. Ambiguity and choice in organizations. Universitersforlaget, Bergen, 69-81.

March, J.G. 1991. Exploration and exploitation in organizational learning. Organ. Sci. 2 71-87.

Mowery, D.C., J.E. Oxley, B.S. Silverman. 1996. Strategic alliances and interfirm knowledge transfer. Strategic Management J. 17(Winter Special Issue) 77-91.

Narayanan, M.P. 1985. Managerial incentives for short-term results. The J. of Finance 40(5) 1469-1484.

Nelson, R., S. Winter. 1982. An evolutionary theory of economic change. Belknap Press of Harvard University Press, Cambridge, MA.

Nickerson, J.A., B.S. Silverman. 2003. Why firms want to organize efficiently and what keeps them from doing so: Inappropriate governance, performance, and adaptation in a deregulated industry. Admin. Sci. Quart. 48(3) 433-465.

Nohria, N., R. Gulati. 1996. Is slack good or bad for innovation? Acad. of Management J. 38(5) 1245-1264.

O'Reilly, C.A., M.L. Tushman. 2004. The ambidextrous organization. Harvard Bus. Rev. 82(4) 74-81.

Park, S.H., R. Chen, S. Gallagher. 2002. Firm resources as moderators of the relationship between market growth and strategic alliances in semiconductor start-ups. Acad. of Management J. 45 527-545.

Reuer, J.J., A. Arino. 2007. Strategic alliance contracts: Dimensions and determinants of contractual complexity. Strategic Management J. 28(3) 313-330.

Rosenkopf, L., A. Nerkar. 2001. Beyond local search: Boundary spanning, exploration, and impact in the optical disk industry. Strategic Management J. 22 287-306.

Rothaermel, F.T. 2001. Incumbent's advantage through exploiting complementary assets via interfirm cooperation. Strategic Management J. 22 687-699.

Rothaermel, F.T., D.L. Deeds. 2004. Exploration and exploitation alliances in biotechnology: A system of new product development. Strategic Management J. 25(3) 201-222.

Rowley, T., D. Behrens, D. Krackhardt. 2000. Redundant governance structures: An analysis of structural and relational embeddedness in the steel and semiconductor industries. Strategic Management J. 21 369-386.

Rudy, J. 2000. Standard \& Poor's Industry Surveys - Computers: Software 1-38.

Schilling, M.A., K.H. Steensema. 2002. Disentangling the theories of firm boundaries: A path model and empirical test. Organ. Sci., 13(4) 387-401.

Sidhu, J.S., H.R. Commandeur, H.W. Volberda. 2007. The multifaceted nature of exploration and exploitation: Value of supply, demnand, and spatial search for innovation. Organ. Sci. 18(1) 20-38.

Stock, J. H., J. H. Wright, M. Yogo. 2002. A survey of weak instruments and weak identification in generalized method of moments. J. of Bus. and Econom. Statistics. 20(4) 518-529.

Stuart, T.E. 2000. Interorganizational alliances and the performance of firms: A study of growth and innovation rates in a high-technology industry. Strategic Management J. 21(8) 719-811.

Stuart, T.E., H. Hoang, R. Hybels. 1999. Interorganizational endorsements and the performance of entrepreneurial ventures. Admin. Sci. Quart. 44 315-349.

Tobin, J. 1958. Estimation for relationships with limited dependent variables. Econometrica 26(1) 24-36.

Tushman, M.L., P. Anderson, C.A. O'Reilly. 1997. Technology cycles, innovation streams, and ambidextrous organizations: Organizational renewal through innovation streams and strategic change. M.L. Tushman, P. Anderson, eds. Managing strategic innovation and change. Oxford University Press, Oxford, 3-23.

Tushman, M.L., C.A. O'Reilly. 1996. Ambidextrous organizations: Managing evolutionary and revolutionary change. California Management Rev. 38(4) 8-29.

Uzzi, B. 1996. The sources and consequences of embeddedness for the economic performance of organizations: The network effect. Amer. Sociological Rev. 61 674-698.

Vassolo, R. S., J. Anand, T. B. ve Folta. 2004. Non-additivity in portfolios of exploration activities: A real options-based analysis of equity alliances in biotechnology. Strategic Management J. 25(11) 1045-1061.

Zahra, S.A., G. George. 2002. Absorptive capacity: A review, reconceptualization, and extension. Acad. of Management Rev. 27(2) 185-203.

Zollo, M., J.J. Reuer, H. Singh. 2002. Interorganizational routines and performance in strategic alliances. Organ. Sci. 13(6) 701-713. 